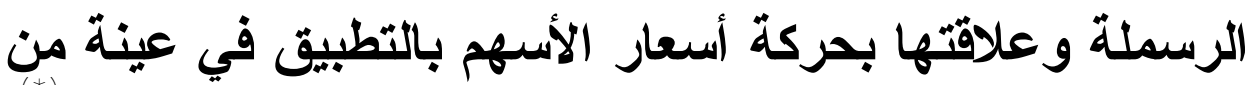

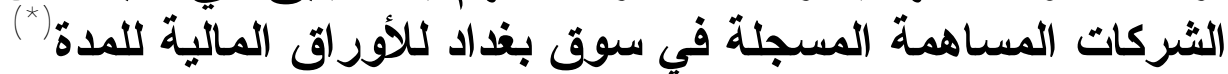 r.. 1- 199r
}

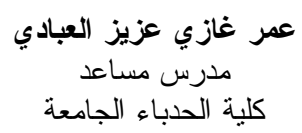

\author{
الاكتور سرمد كوكب الجميل \\ أستاذ مساعد لقنم العلوم المالية و المصرفيلة \\ كلية الادارة والاقتصاد

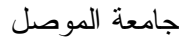

\section{المستخلص الص}

تتاولت الدراسة الحالية تحليل الأثر بين عملية الرسملة التي تجريها الثركات المساهمة وبين

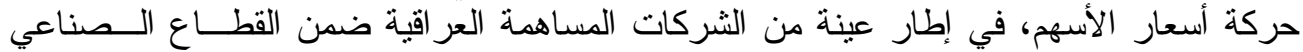

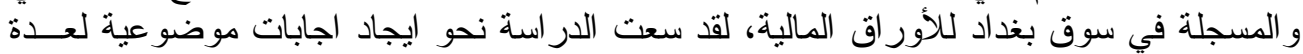

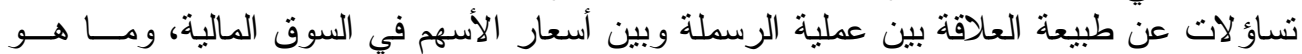

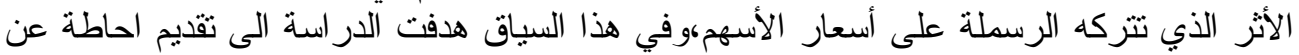

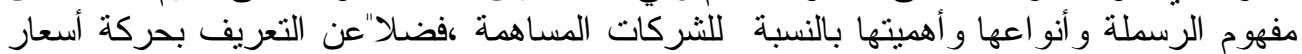

\section{مقدمة}

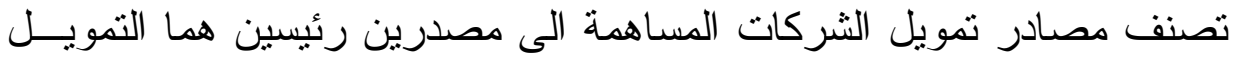

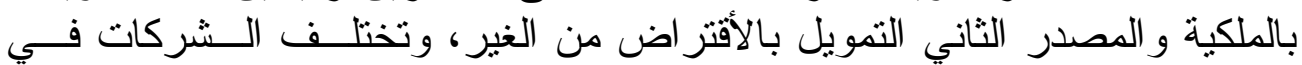

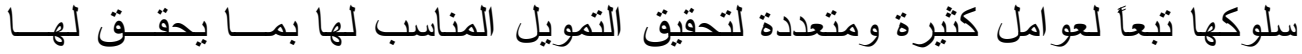

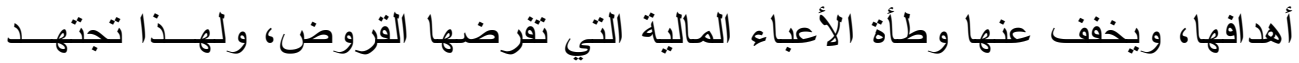

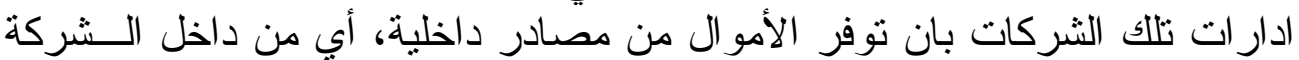

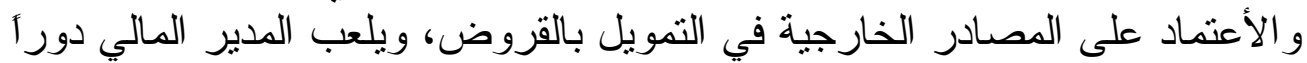

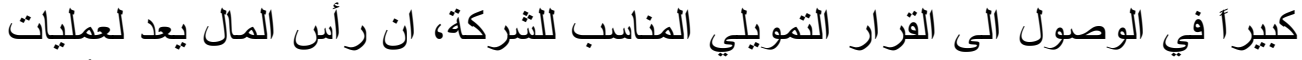

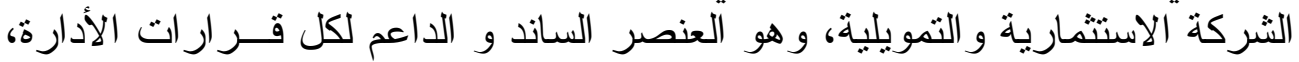

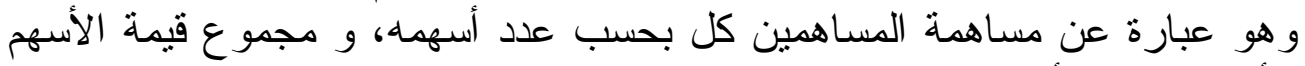

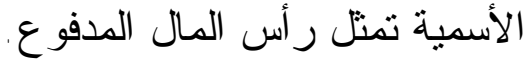
تتناول الدر اسة موضوع الرسملة التي يقصد بها لتها التحويل لراس اس المال بالزيادة،

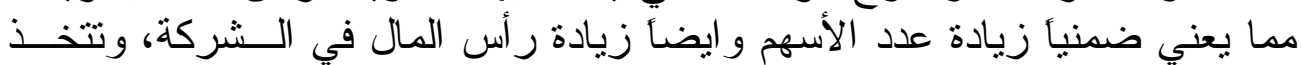

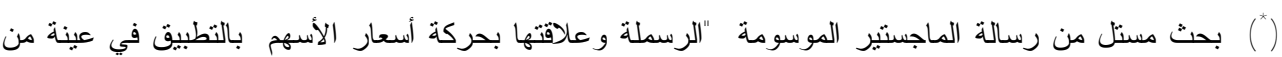

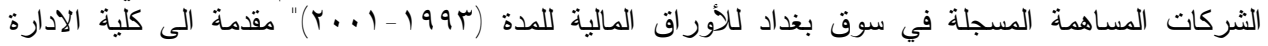


عملية الرسملة اشكالا متعددة منها إصدار أسهم جديدة او ضم احتياطيات معينة الى الى

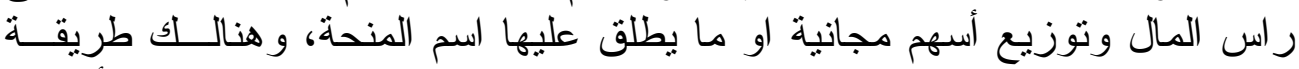

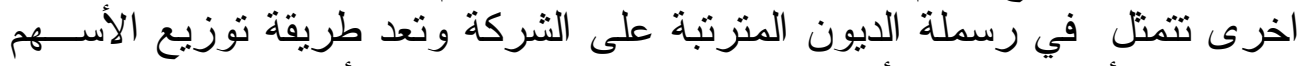

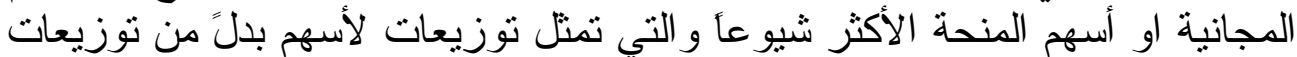

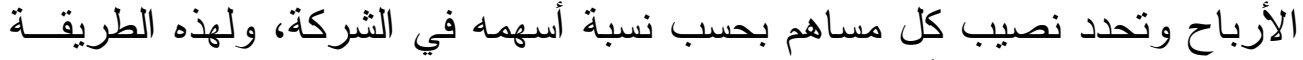
مز ايا كثيرة للشركة ولأدارة وللمساهمين، و هناك ايضاً سلبيات تعاني منها.

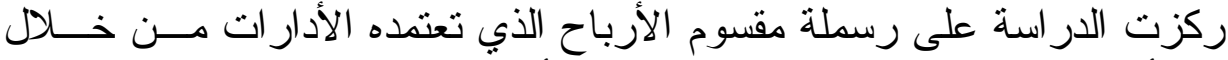

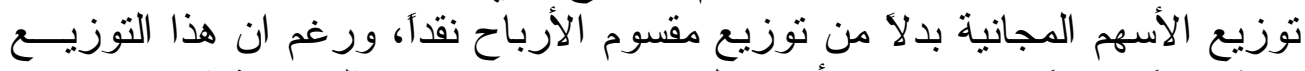

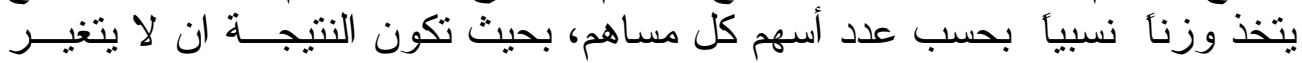

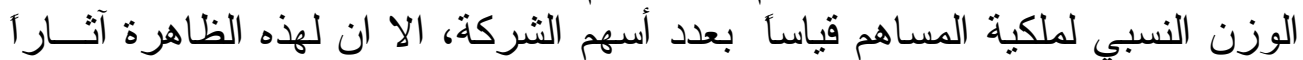

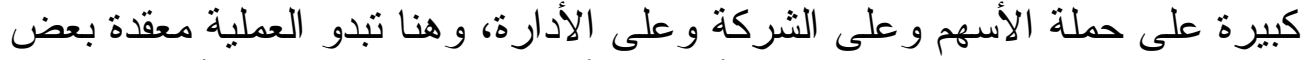

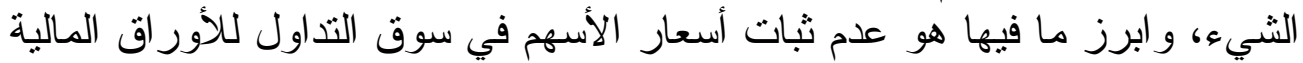

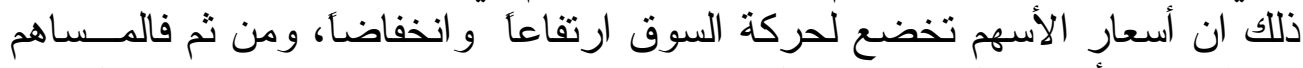

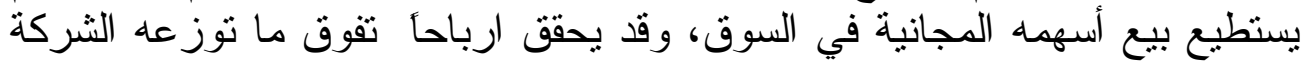

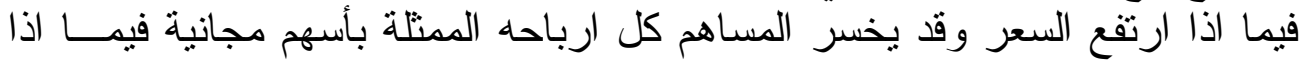
انخفض السعر النع

\section{مشكلة الار اسة}

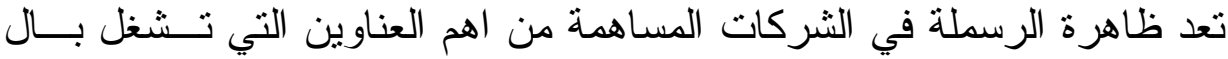

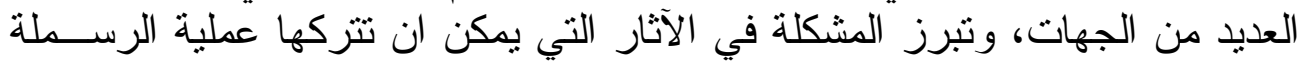

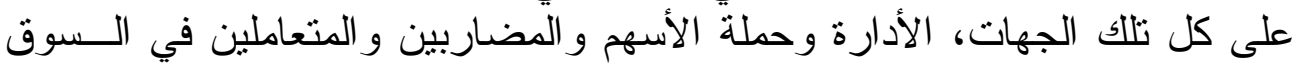

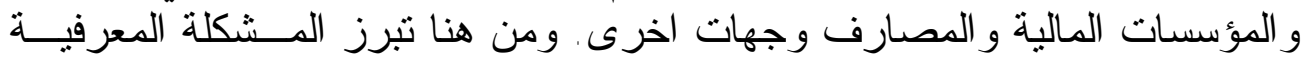

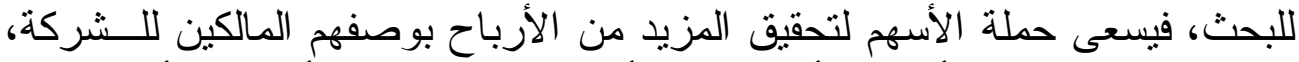

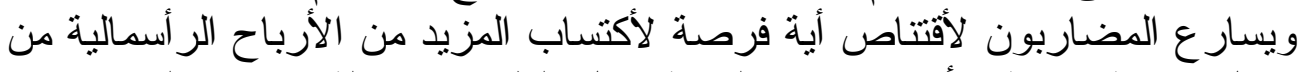

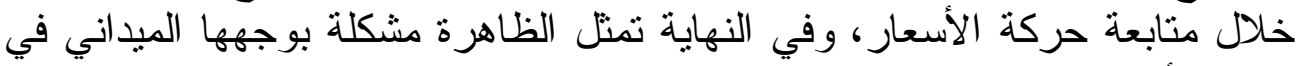

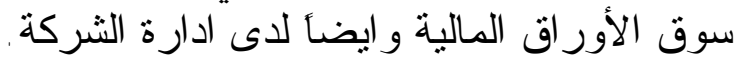

أهمبة الدر اسةة

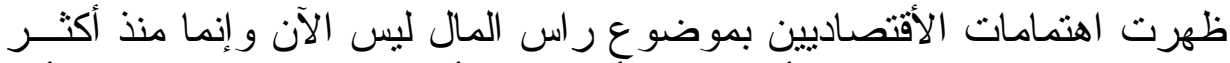

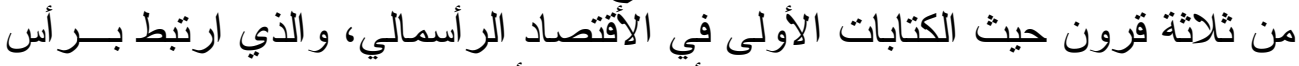

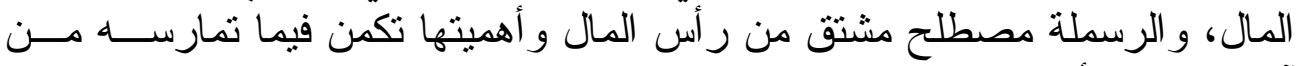

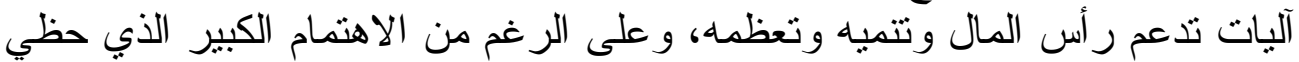

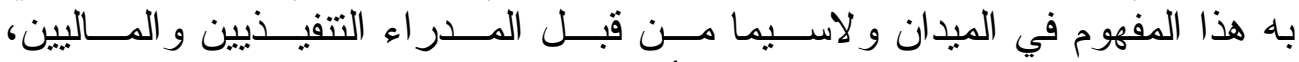

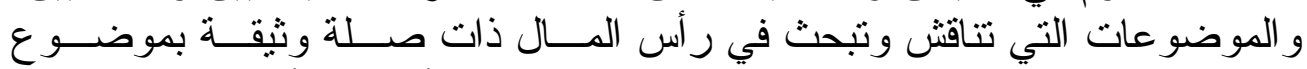
الرسملة، الا ان الجديد في البحث الحالي علافته بحركة أسعار الأسهم وهذا بالتهات التحديد

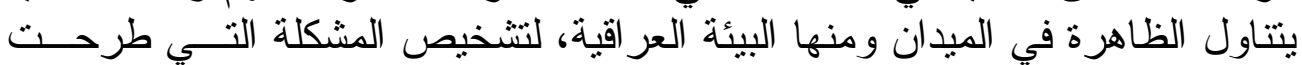




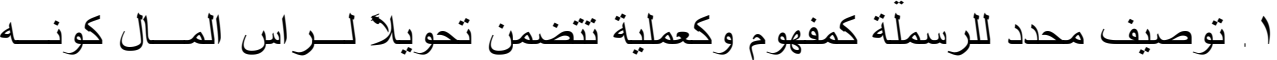

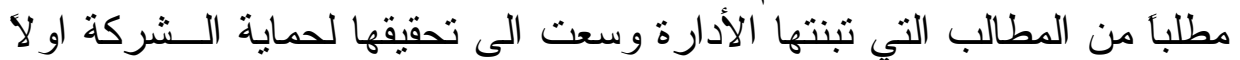

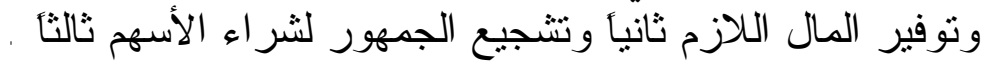

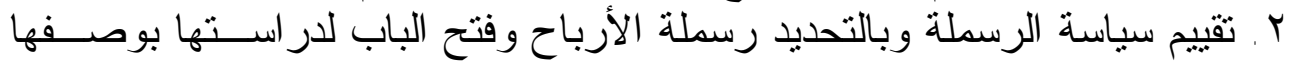

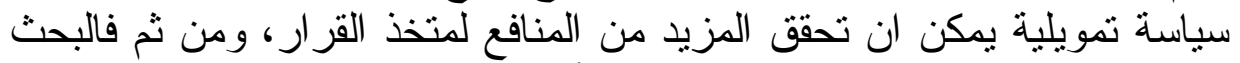

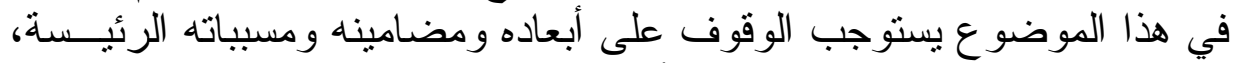

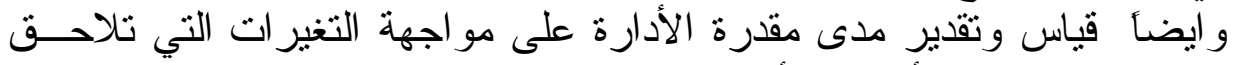

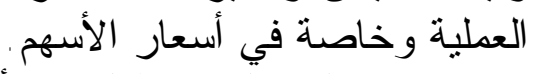

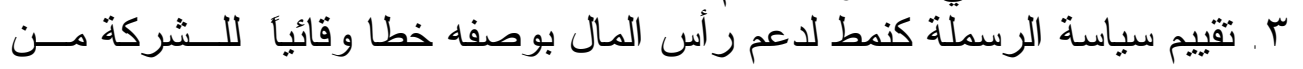

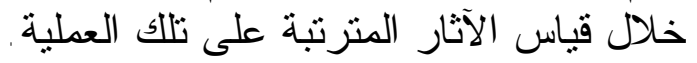

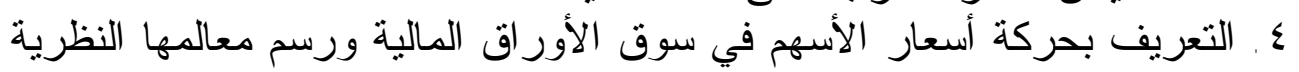
و التطبيقية التي يمكن ان تسهم في فهم آلياتها ومسبباتها.

\section{فرضيات الار اسة}

لغرض تحقيق أهداف الدراسة، بستتد البحث الى الفرضيات العيات الاتية:

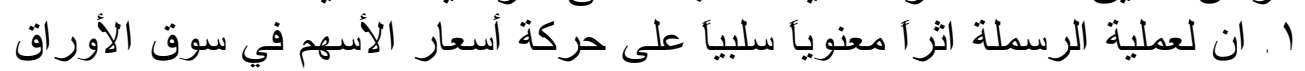

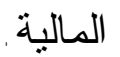
r. ان لحجم التداول اثرأ معنويأ سلبياً على حركة أسعار الأسهم في سوق الأوراق

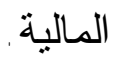

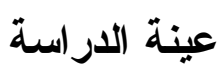

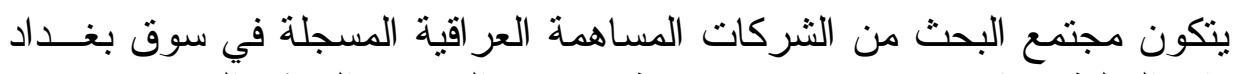

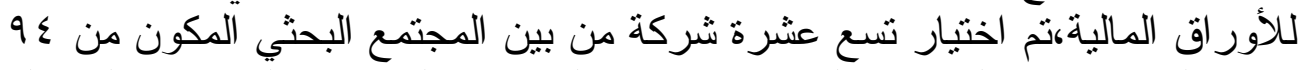

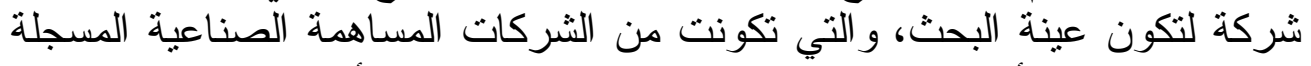

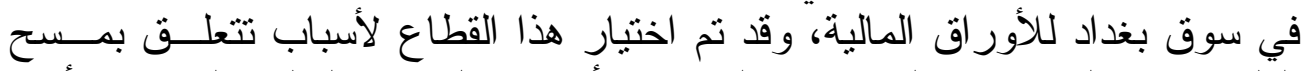

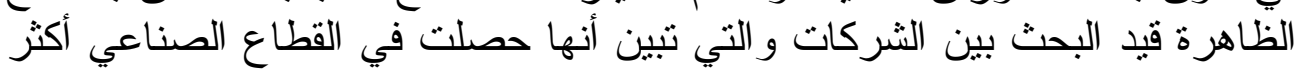
من أب قطاع آخر، وهي كما موضحة في الجدول البن ادناه: 


\section{الجدول الجير}

بيانات تعريفية عن الثركات عينة الدراسة

\begin{tabular}{|c|c|c|c|}
\hline تاريخ الأدر اج في & تاريخ التأسيس & اسم الشركة & 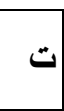 \\
\hline $199 r / T / Y T$ & $19 \wedge \wedge / V / \Gamma$. & |العر اقية للسجاد و المفروشات & 1 \\
\hline $199 r / T / Y T$ & 1919 & |الخياطة الحديثة & r \\
\hline $199 Y / T / Y T$ & $1919 / 0 / 9$ & |نينو للصناعات الغذائية & $r$ \\
\hline $199 r / T / Y T$ & $19 \wedge 9 / V / r$. & الخازر لإنتاج المو اد الإنشائية & $\varepsilon$ \\
\hline $199 Y / T / Y T$ & 1919 & بغداد للمشروبات الغازية & 0 \\
\hline $199 Y / T / Y T$ & $197 r / r / 11$ & |الهلال الصناعية & 7 \\
\hline $199 r / r / r r$ & 1974 & |الوطنية للصناعات الكيماوية & $\mathrm{V}$ \\
\hline $199 r / T / K r$ & $19 V T / V / Y \wedge$ & |الصناعات الالكترونية & $\wedge$ \\
\hline $199 r / \Gamma / K r$ & $1919 / \wedge / K r$ & الفلوجة لإنتاج المو اد الإنشائية & 9 \\
\hline $199 r / r / r T$ & $197 Y / \varepsilon / Y T$ & |الوطنية للصناعات الغذائية & 1. \\
\hline $199 Y / T / Y T$ & 1910 & |العر اقية للصناعات الهندسية & 11 \\
\hline $199 r / T / K r$ & $19 V 7$ & صناعة الأصباغ الحديثة & IT \\
\hline $199 r / T / Y T$ & $197 \varepsilon / 9 / Y \wedge$ & صناعة الدر اجات و الأنابيب المعدنية & $1 \pi$ \\
\hline $199 r / T / K r$ & $19 V 7 / 0 / \% 1$ & إنتاج الألبسة الجاهزة & $1 \varepsilon$ \\
\hline $199 r / T / K r$ & $19 \vee \wedge$ & |العر اقية لصناعة الكارتون & 10 \\
\hline $199 Y / r / Y T$ & $19 \vee 7 / 7 / V$ & صناعة المو اد الإنشائية الحديثة & 17 \\
\hline $199 r / r / r r$ & 1909 & |الصناعات الخفيفة & IV \\
\hline $199 r / T / K r$ & $1919 / 1 / 1$ & |المشروبات الغازية الثمالية & 11 \\
\hline $199 r / T / K r$ & $1917 / 7 / 0$ & الوطنية لصناعات الأثاث المنزلي & 19 \\
\hline
\end{tabular}

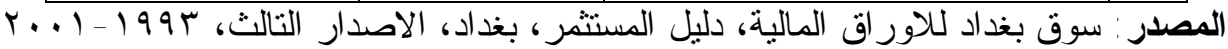

أما المدة الزمنية التي غطاها البحث فهي تمتذ من سنة بو99 1 - 1 . . ب اي تشعة

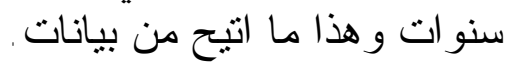

$$
\text { مصادر البيانات }
$$

اعتمد البحث على مصادر متعددة للبيانات ويقف على رأسها الكثوفات المالية للشركات قيد البحث، والتي تتضمن الميز انيات السنوية، و ايضاً النشرات التهات الـشهرية

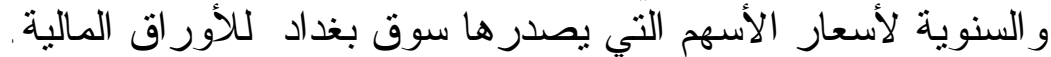
أدوات الار اسنة

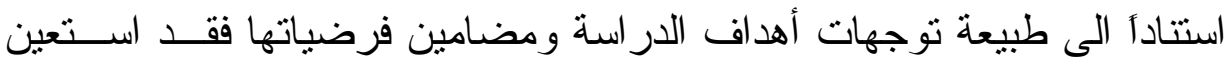

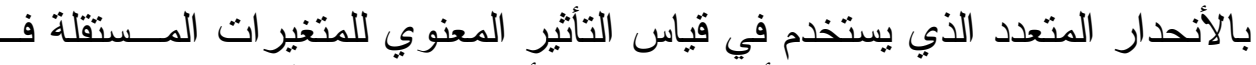
المتغير المعتمد، وقد استخدم الأنحدار المجمع أو المتسلـسل (Regression Pooled)

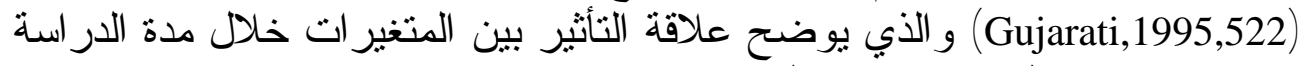

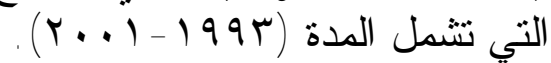




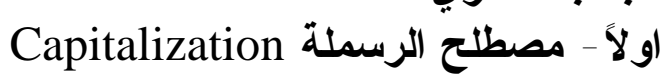 \\ اولاًاتب - مصطلح النظري}

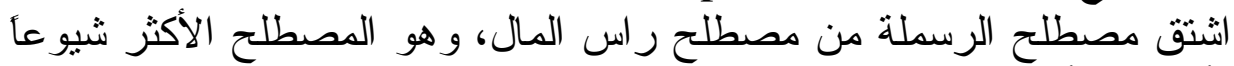

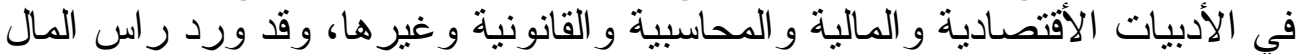

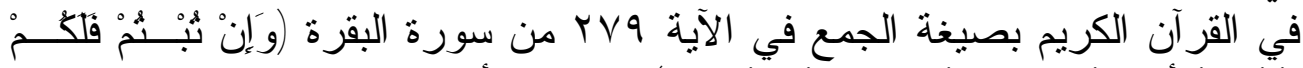

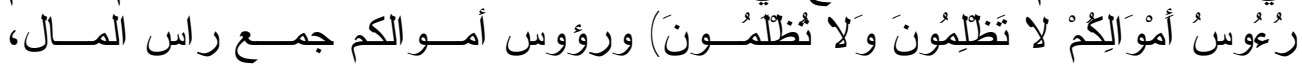

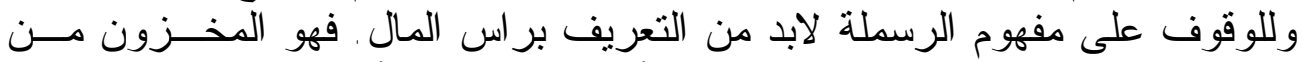

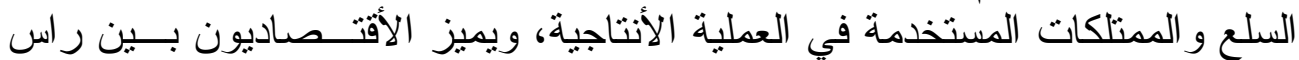

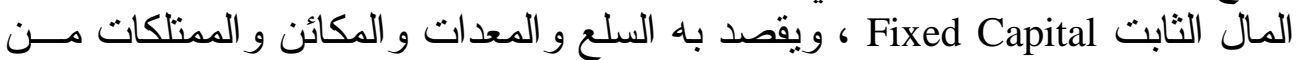

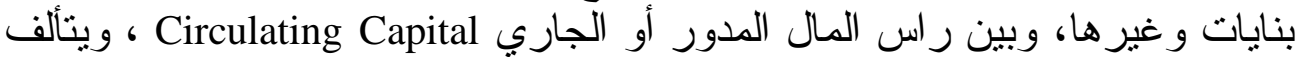

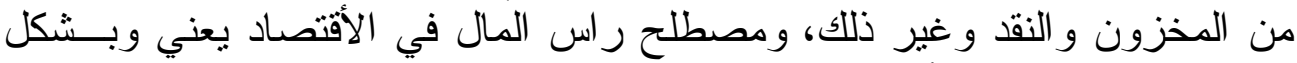

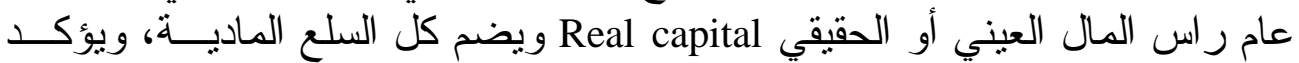

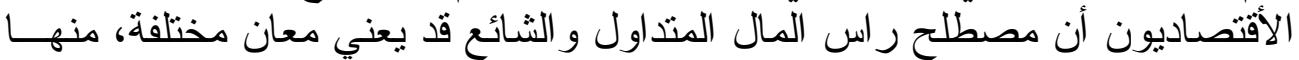

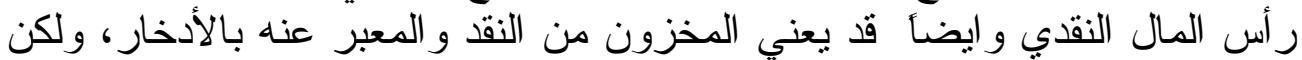

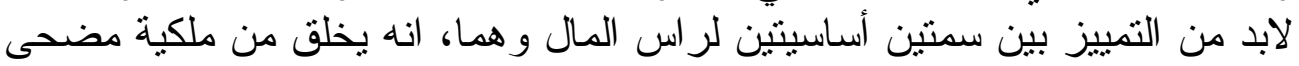

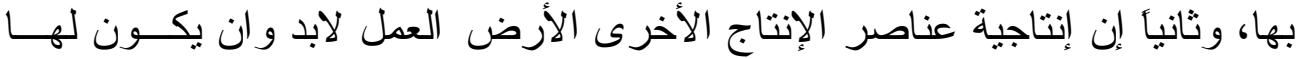

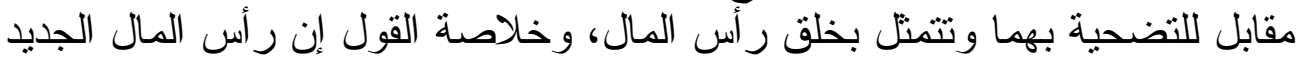

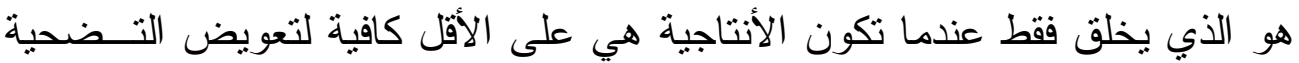

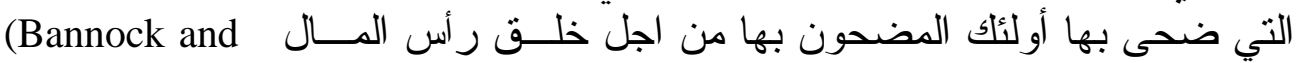

.Others, 1982, 63)

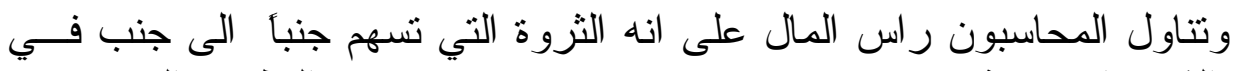

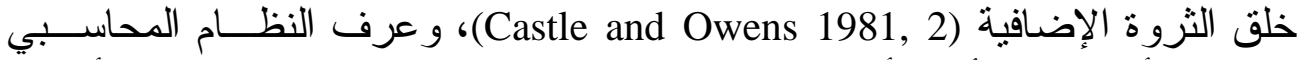

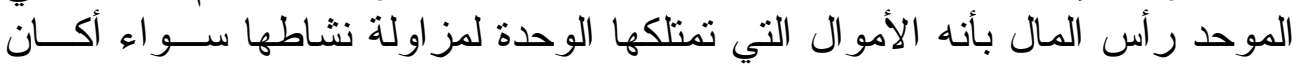

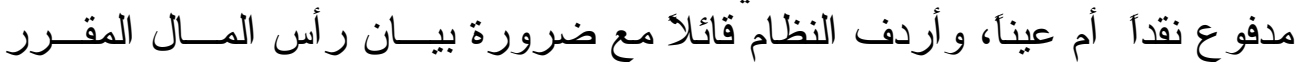

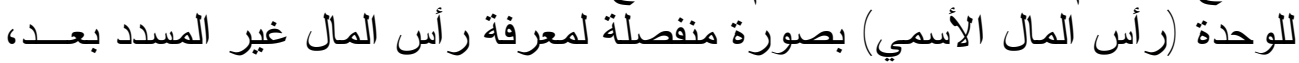

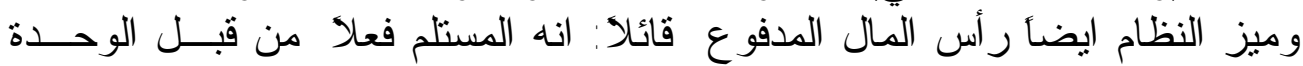

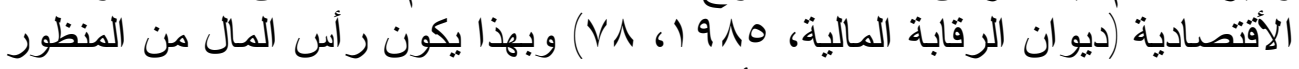

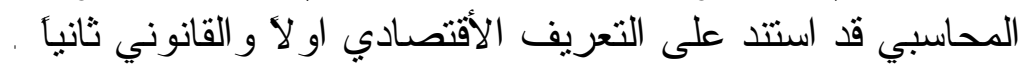

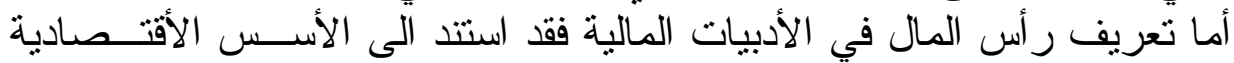

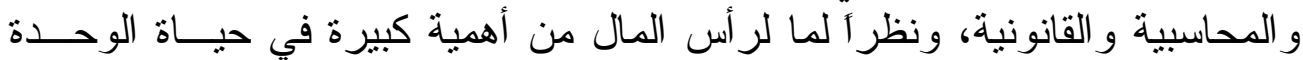

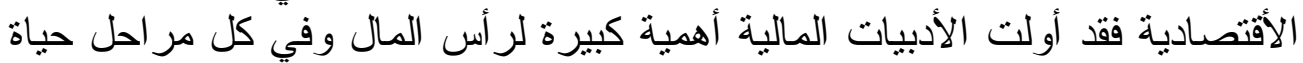
منظمة الأعمال منذ بدء تأسيسها وحتى في نهايتها عند الفالاسها الرالية او الغلاق أعمالها.

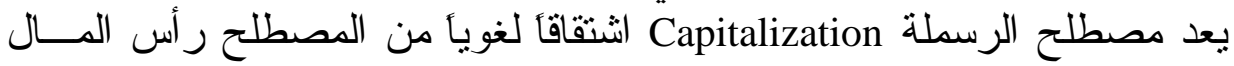

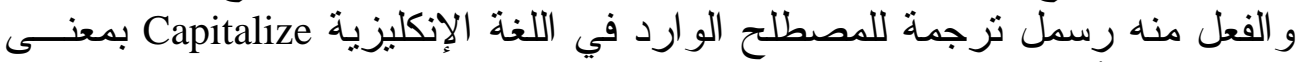

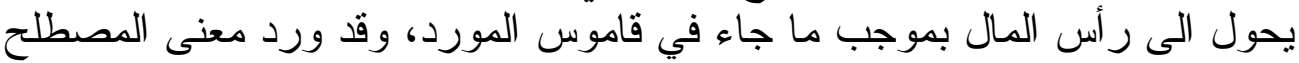

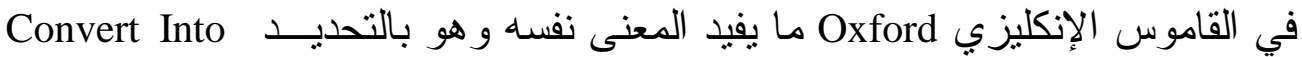
(Hornby, 1982,85)Use As Capital 


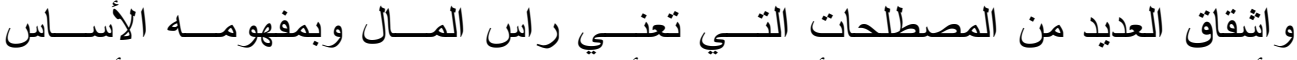

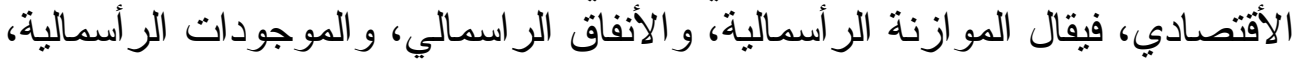

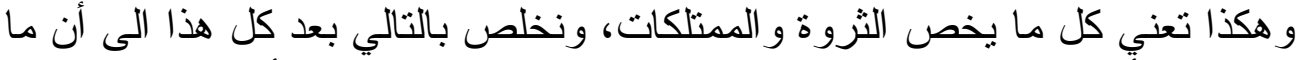

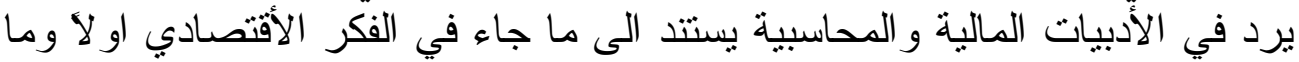

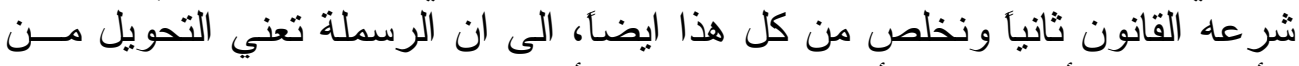

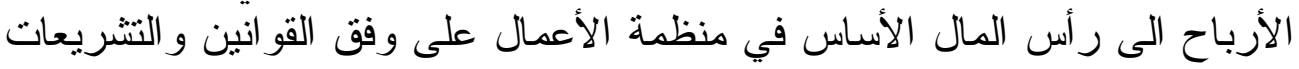

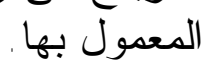

ثانياً - إبعاد مفهوم الرسملة

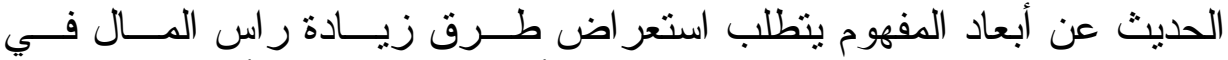

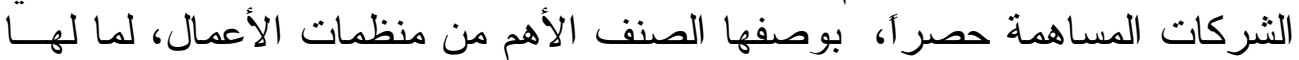

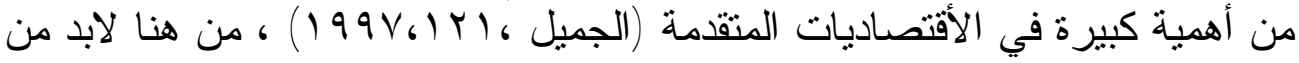

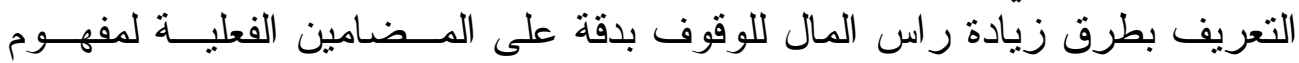

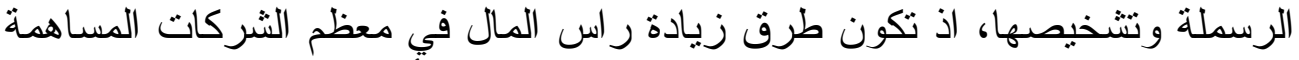

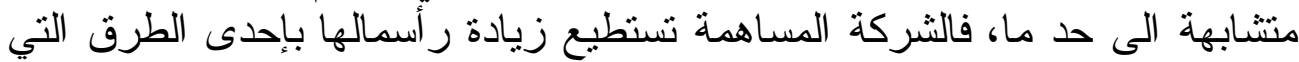

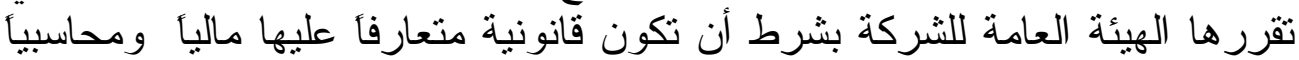

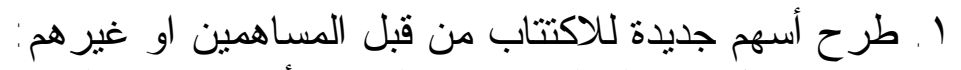
ومنها:

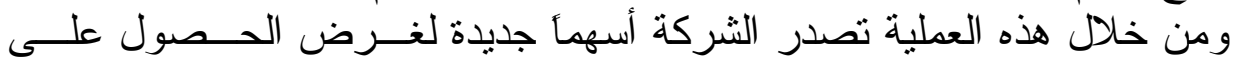

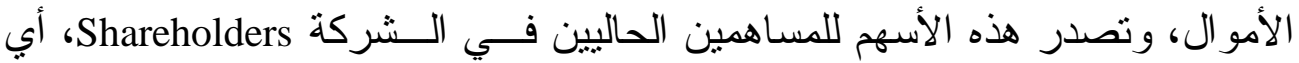

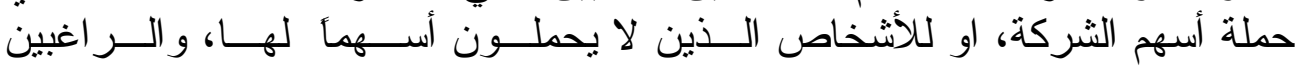
بالاستثمار في اسمها، و هنا على الثركة الثركة مر اعاة الآتي: أ. تكلفة الأصدار

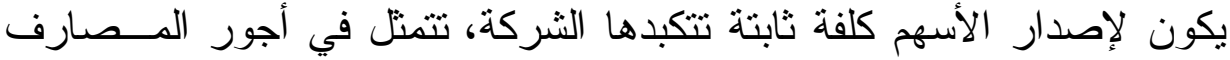

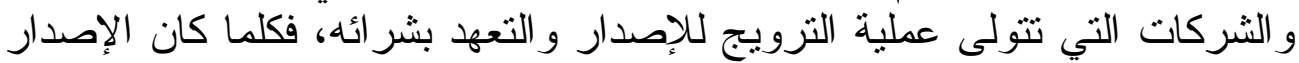

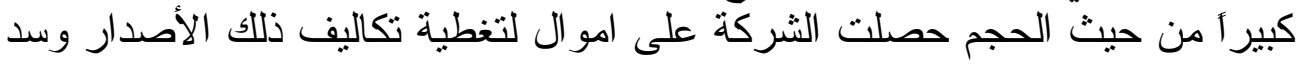

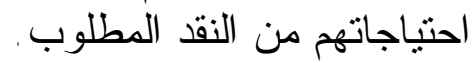
ب. التخفيف في السيطرة

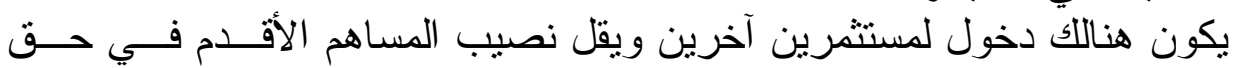
التصويت مما يخفف من سيطرة حملة الأسهم (Melaney, 2000, 203).

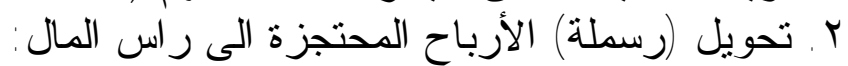

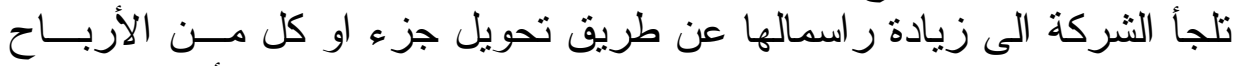

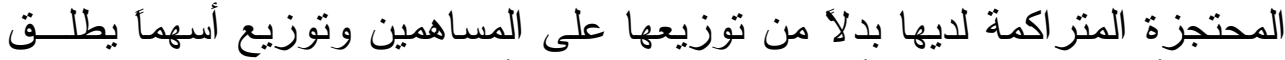

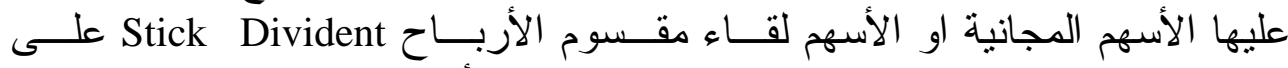

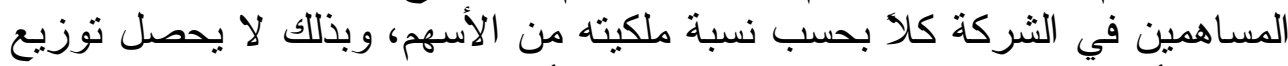

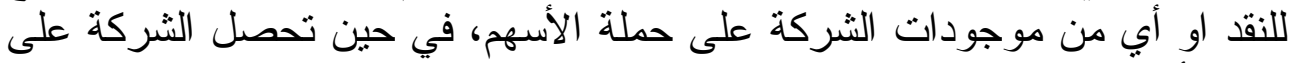

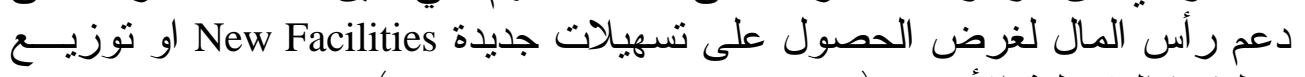

عملياتها التشغيلية الأخرى (Fess and Warren, 1984, 446). 
r r بحويل (رسملة) ديون الثركة:

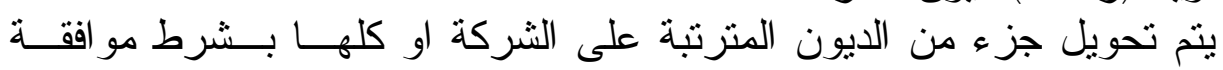

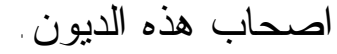

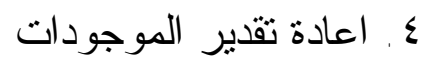

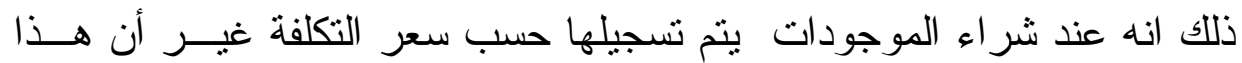

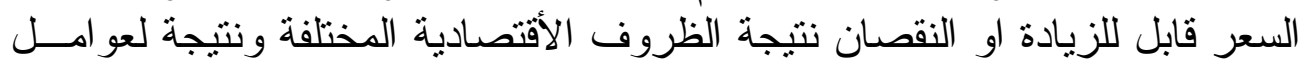

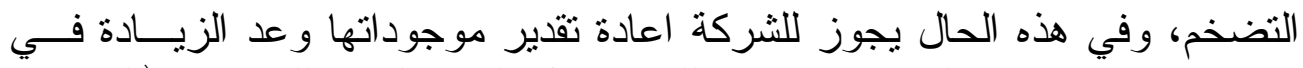

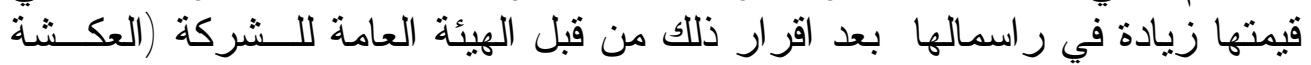

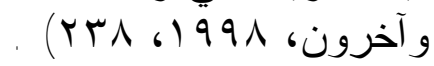

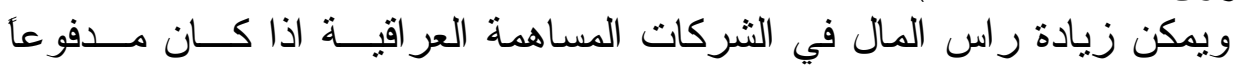

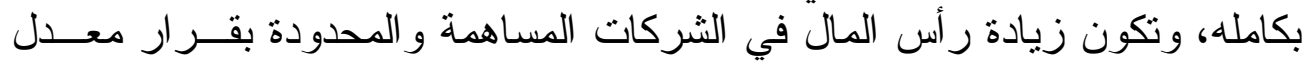

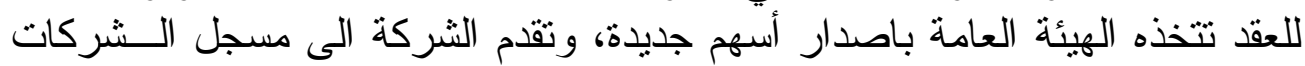

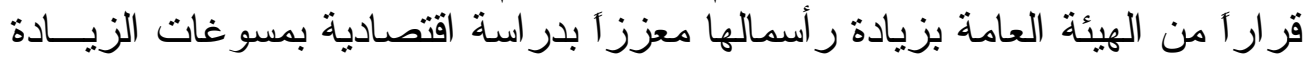

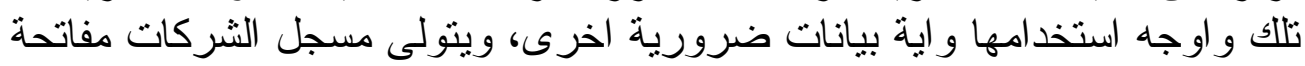

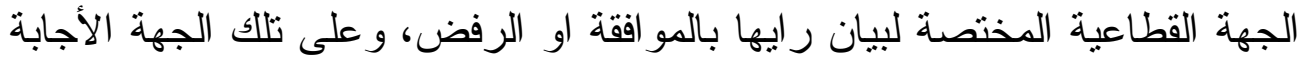

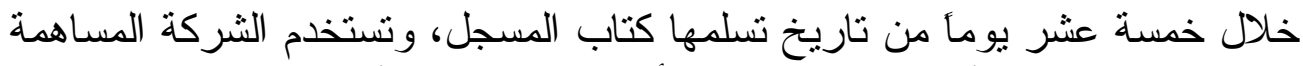

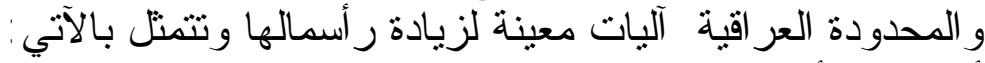

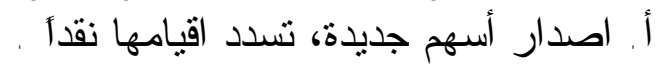

ب. تحويل كل امو ال الفائض المتر اكم او جزء هُ منها الى أسهم توز على على المساهمين

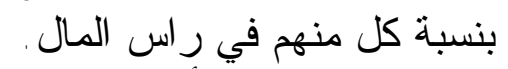

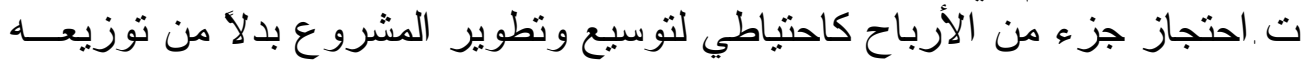

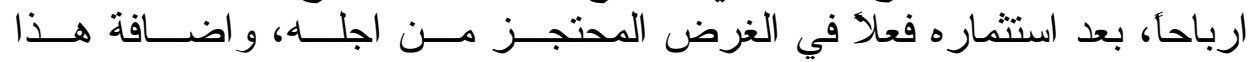

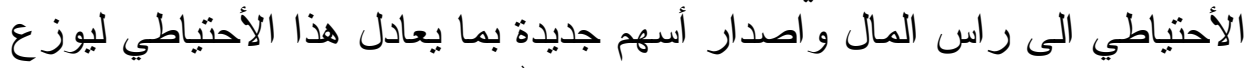

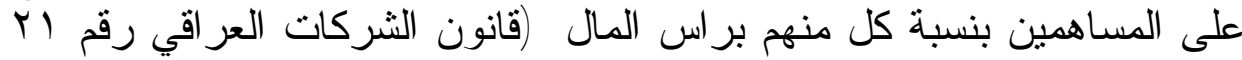

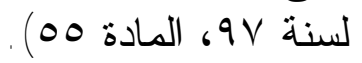

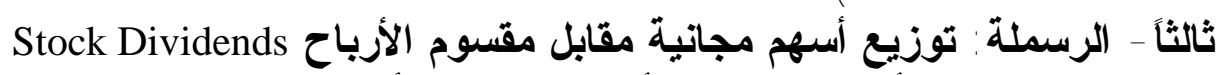

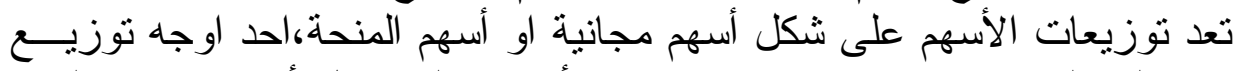

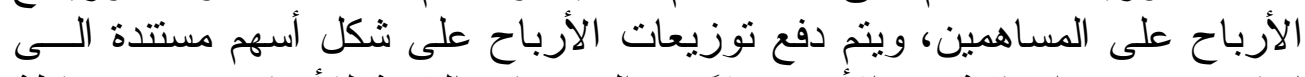

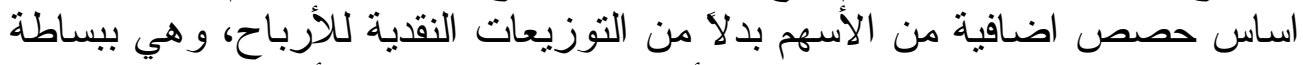

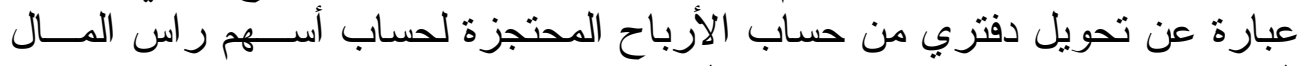

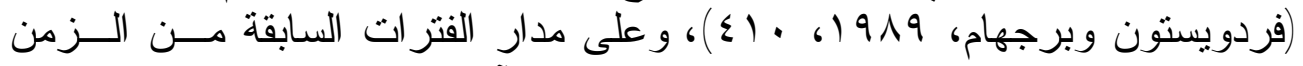

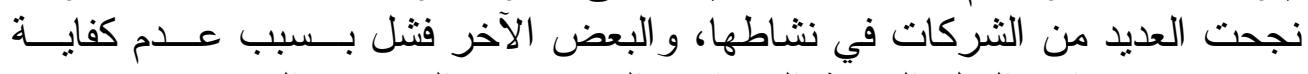

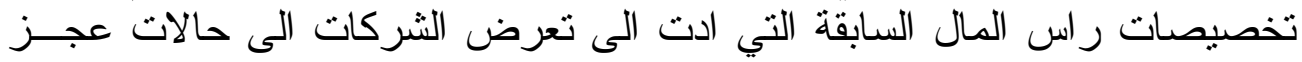

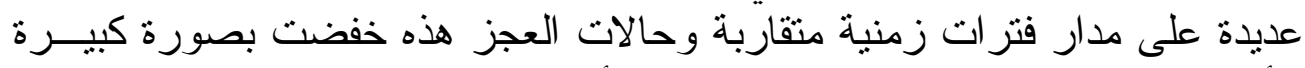

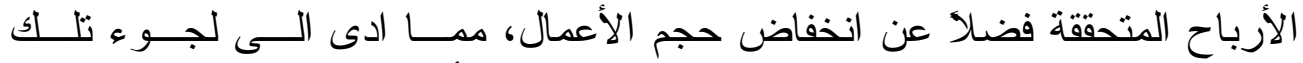

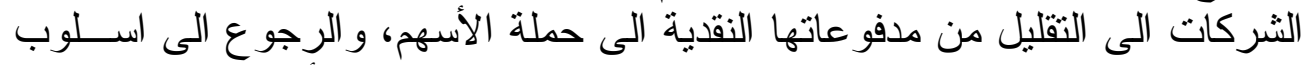

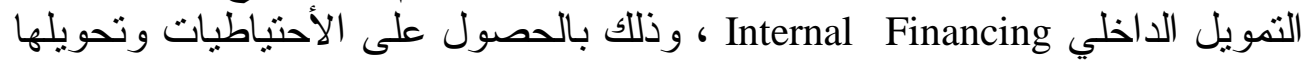




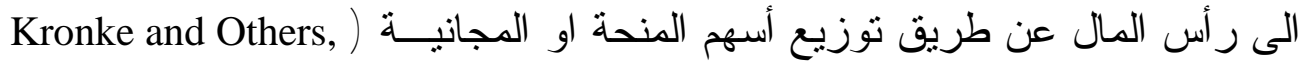

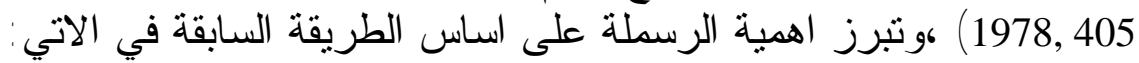

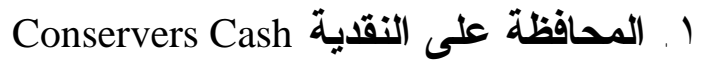

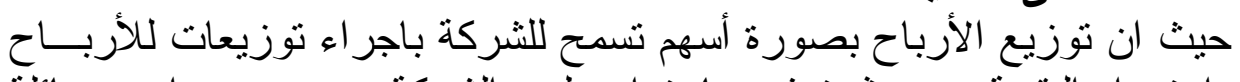

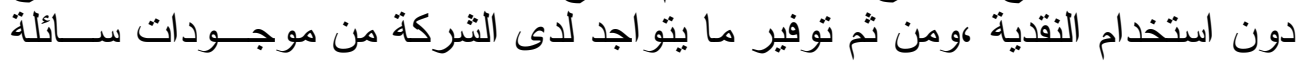

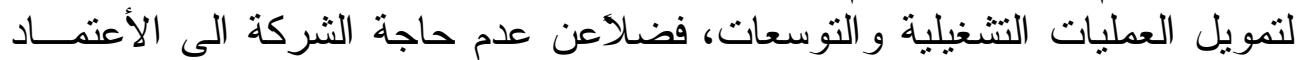

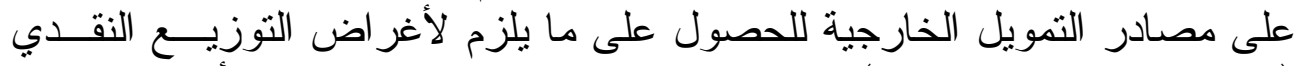

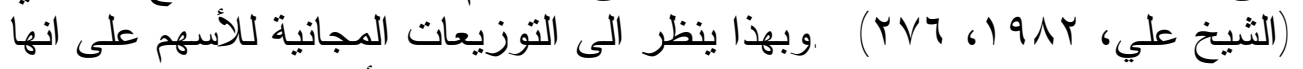

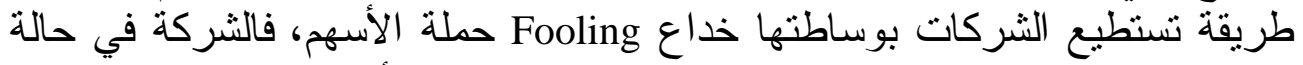

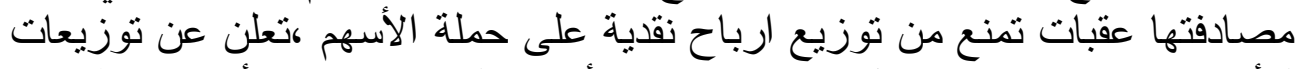

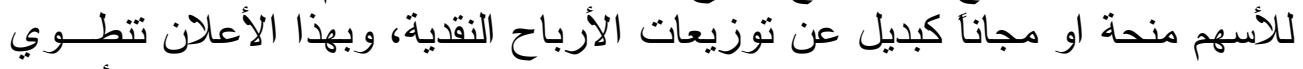

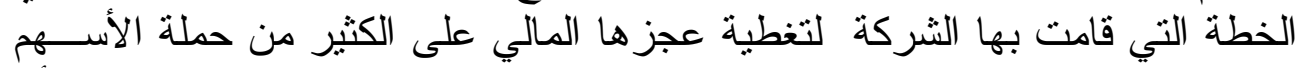

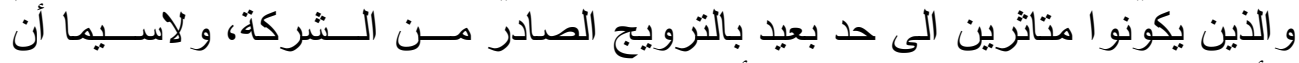

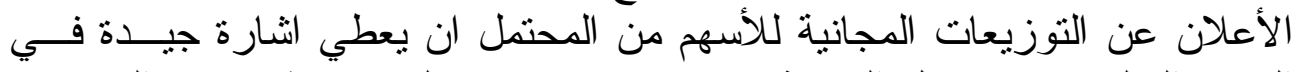

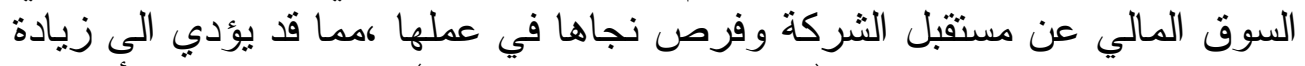

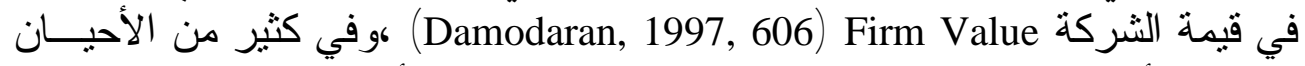

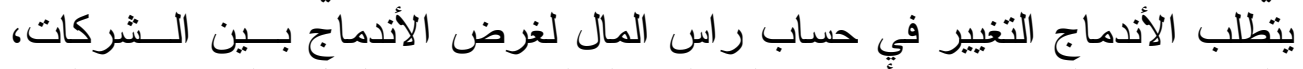

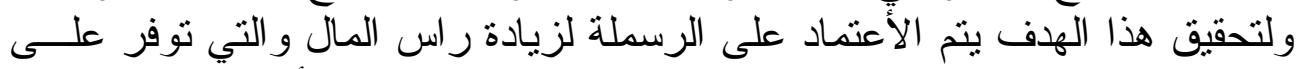

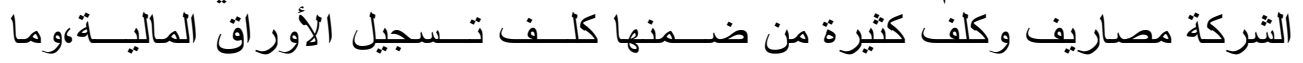

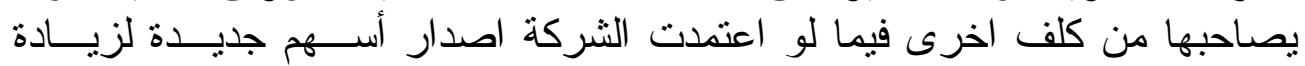

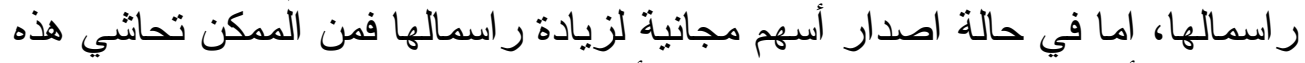

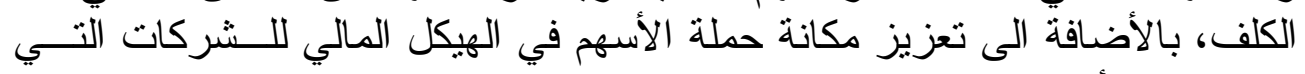
تظهر بعد الأندماج. Kronke and Others, 1978, 408) r. دعم قدرة الشركة على تحقيق المزيد من الأرباح في المستقبل

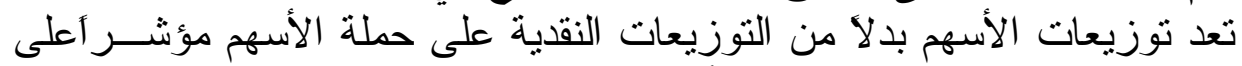

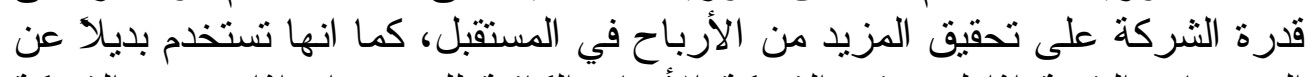

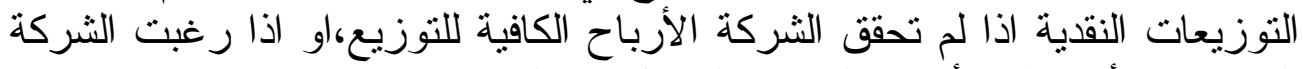

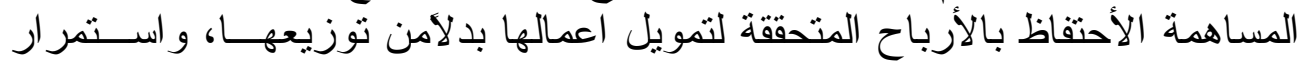

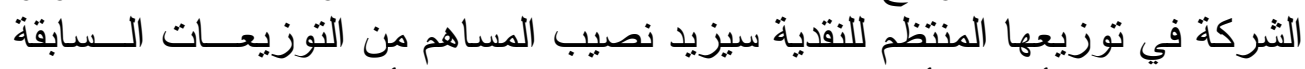

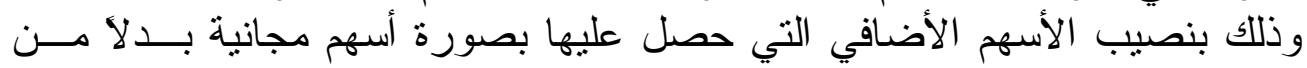

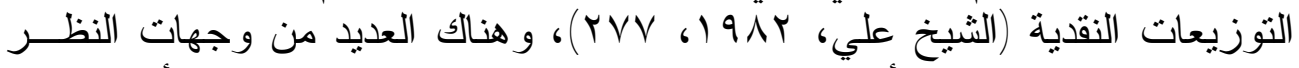

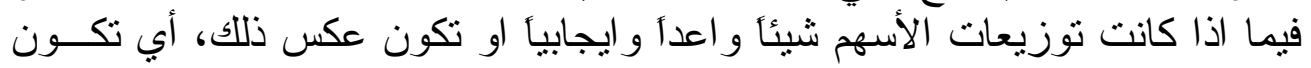

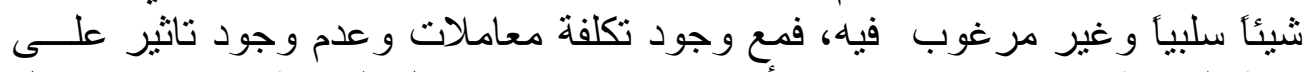

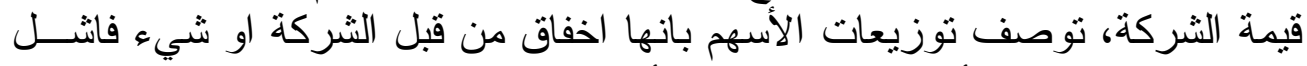
Lamons

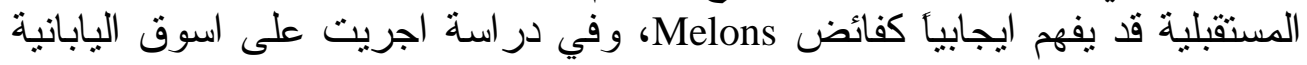
و الثركات المدرجة فيه وجد ان رد فعل السوق كان ايجابياً Positively عند اعلانها 
عن التوزيعات المجانية لأسهم و المرتبطة بتوزيع نقدي مستقبلي و التي سوف تزيد من حجم الأمو ال المستلمة من قبل المساهمين (Kato and Tsay, 2002,21) .

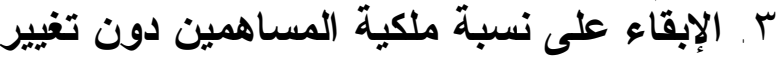

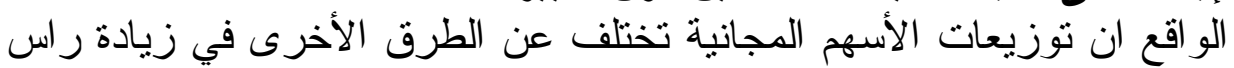

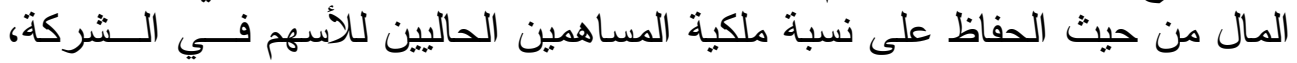

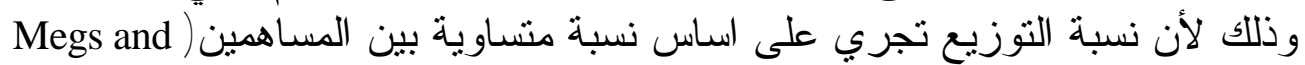
.) (Meigs, 1984, 643

ع ـ إبقاء مستوى السعر ضمن حركة التداول

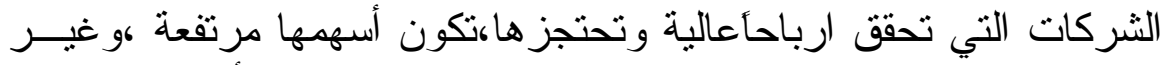

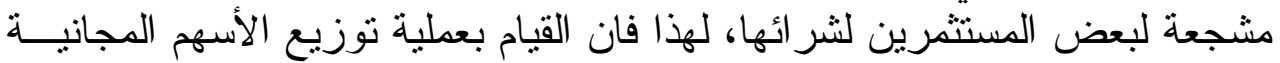

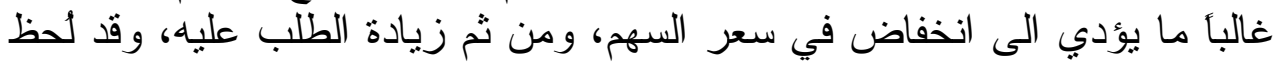

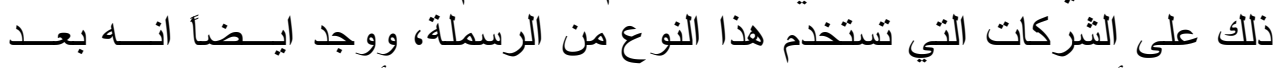

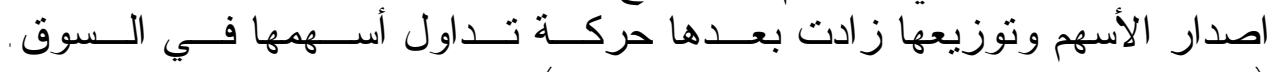
. (Mosbacher and Burkhardt, 1988, Abstract)

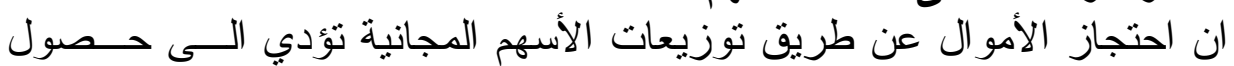

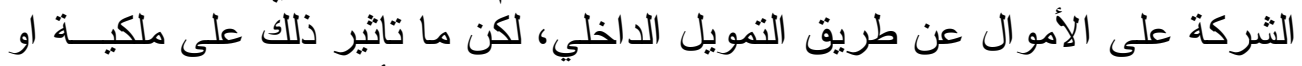

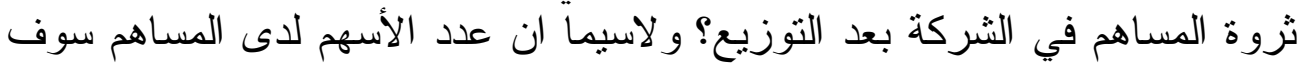

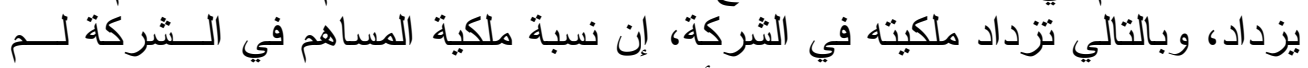

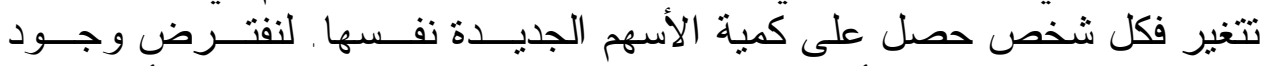

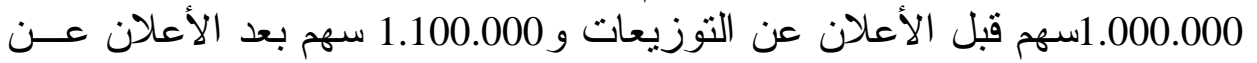

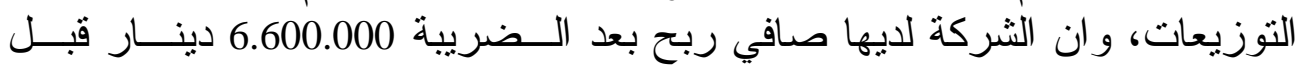

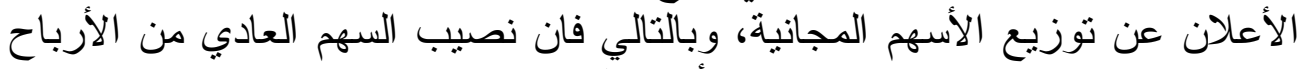

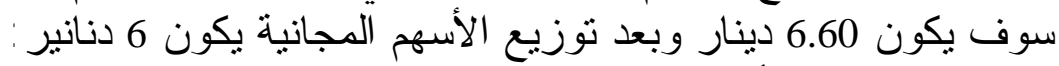

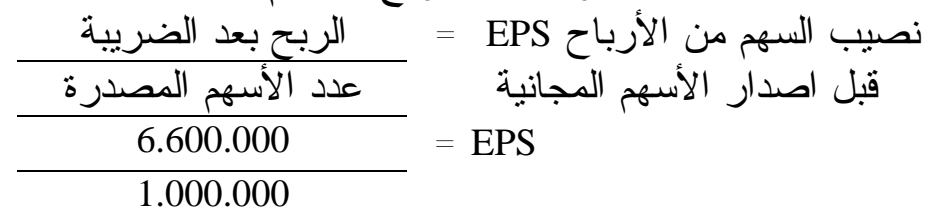

زئار $6.6=$

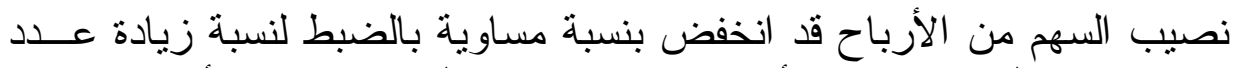

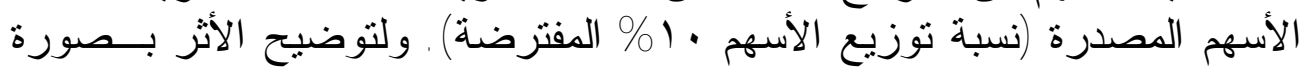

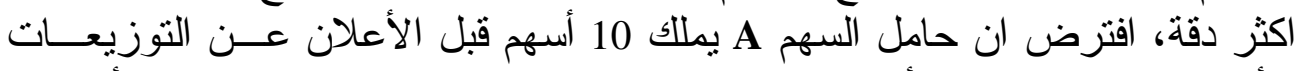

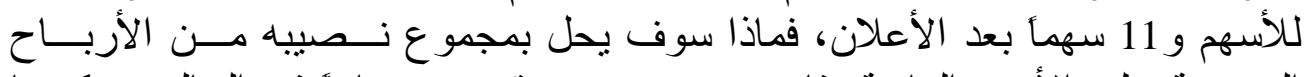

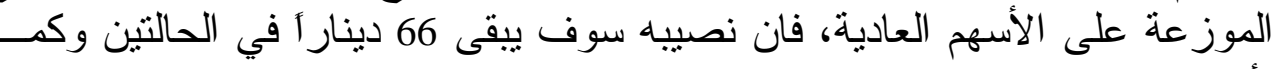
نصيب المساهم من الأرباح = عدد الأسهم التي يحملها × نصيب السهم من الأرباح نصأتي:

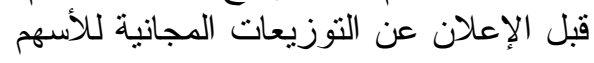




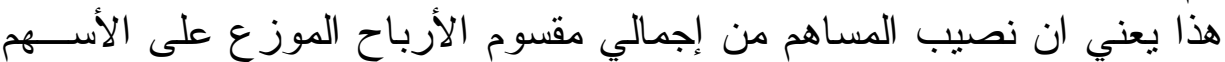

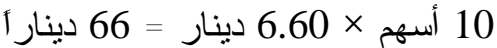
بعد الإعلان عن التوزيعات المجانية للأسهر 66 دينار

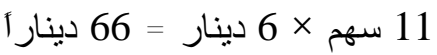

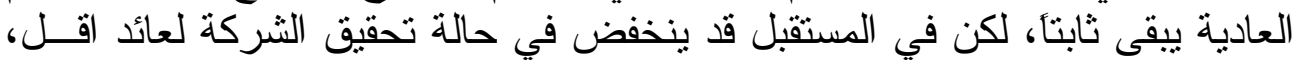

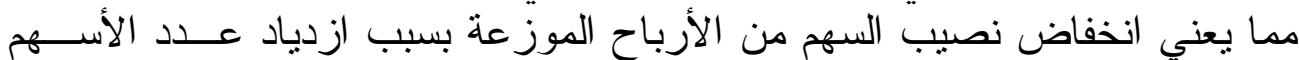

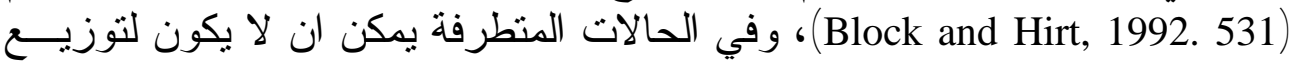

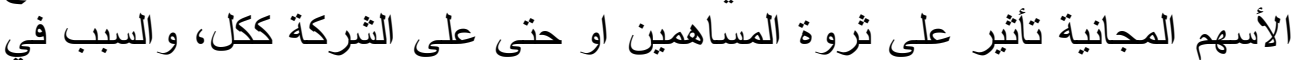

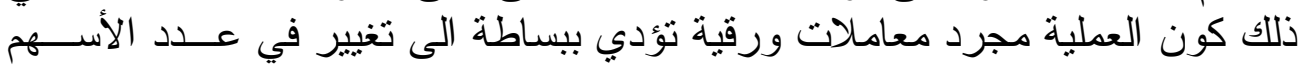

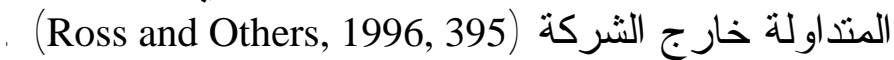

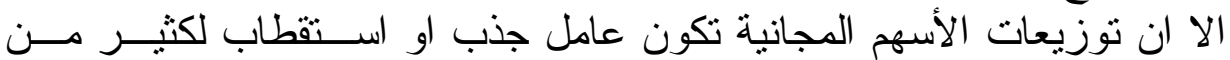

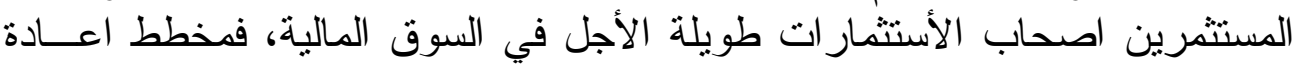

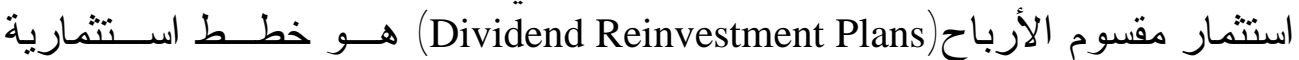
تعرض من قبل الثركة الى حملة الأسهم لغرض شرح وتبرير عملية توزيع الأسهر

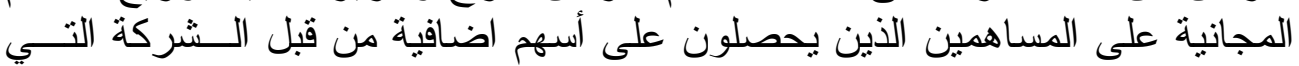

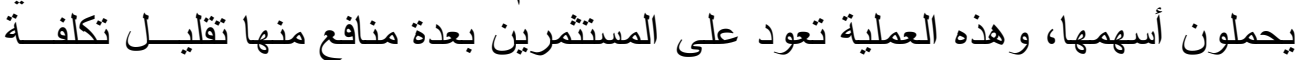

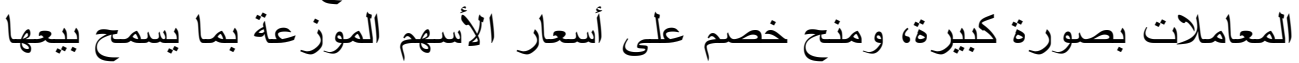
من قبل المستثمر بسعر اعلى في السوق، و امكانية شر اء أســهم بــصورة كـسرية

. (Conrad, 1987, Abstract)

خامساً - تاثير الرسملة على القيمة السوقية للسهم

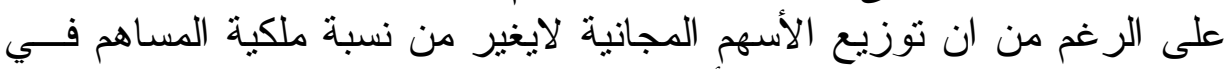

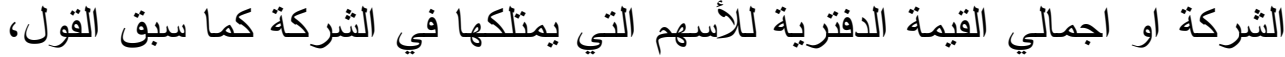

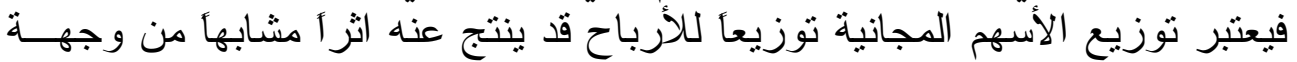

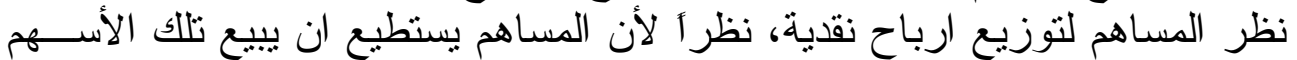

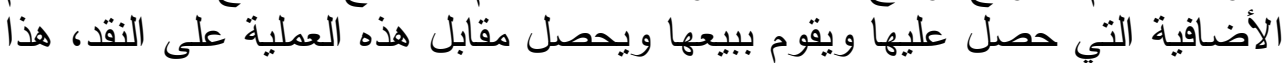

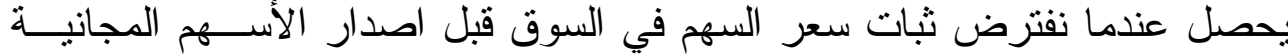
وبعدها، ولكن بالطبع لابد وأن نأخذ اثر زيادة إثر زيادة عدد الأسهم المتذاولة نتيجة

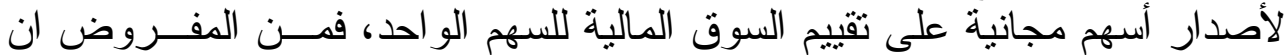

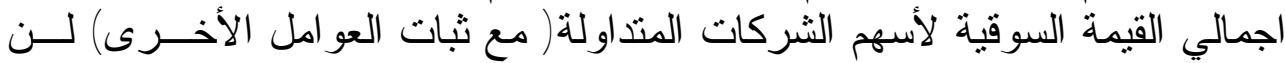

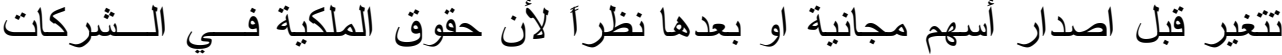

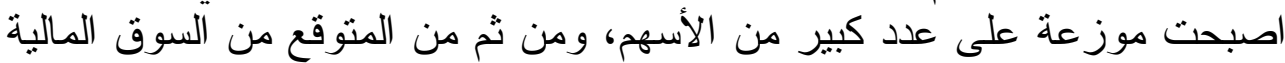

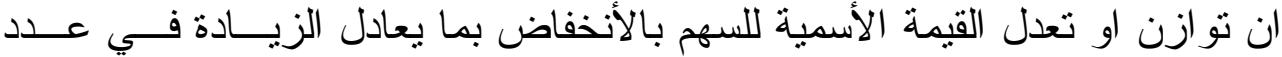

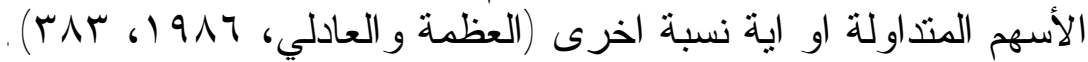

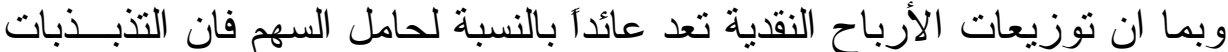

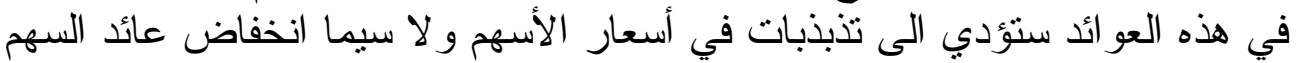

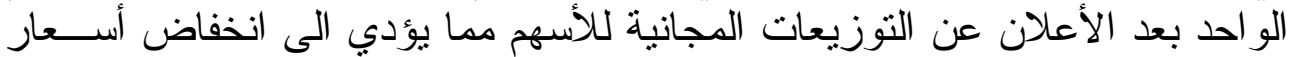

أسهم الثركة ككل في السوق المالية (Dubofsky and French, 1988, Abstract) . 


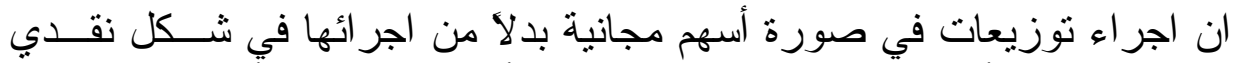

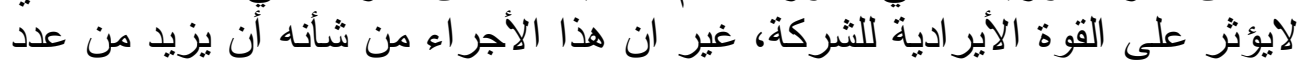

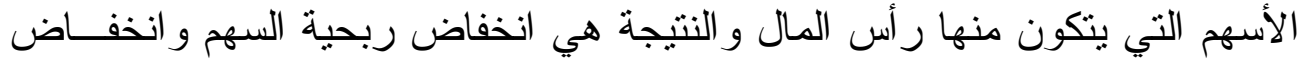
قيمته السوقية بالتبعية.

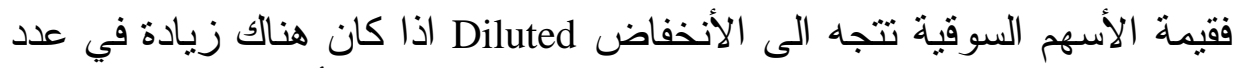

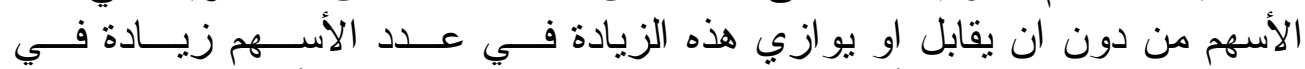

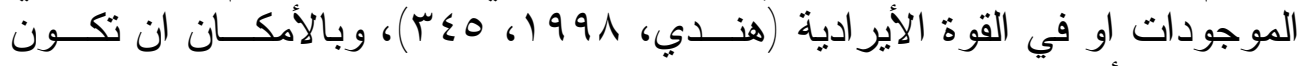

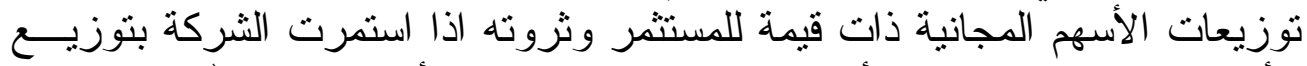

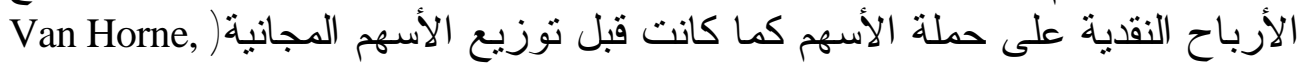
. (1982, 442

\section{سادساً - آثار الرسملة على الشركة}

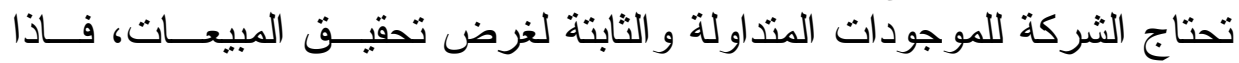

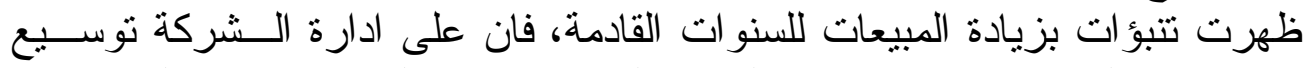

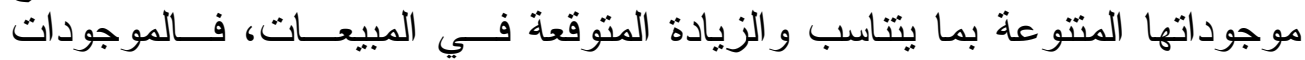

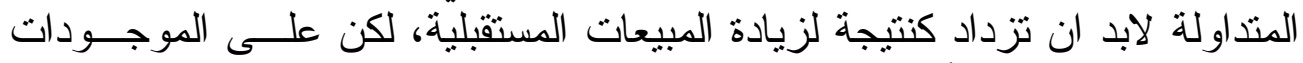

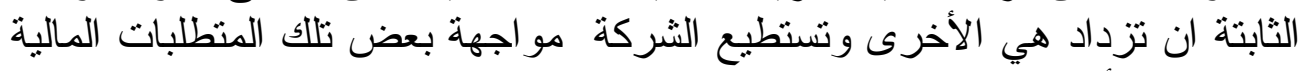

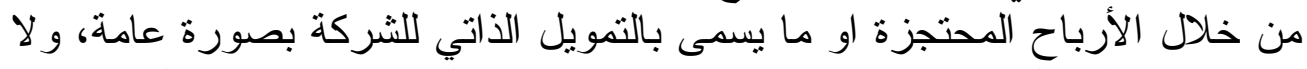

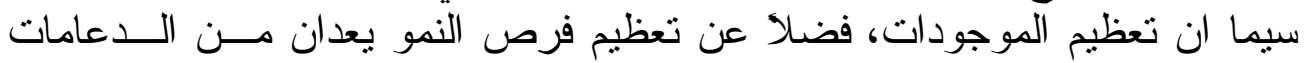

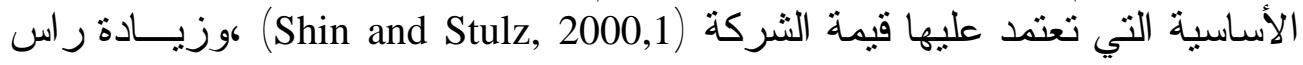

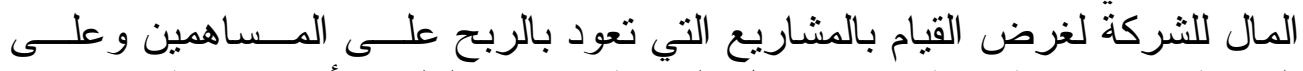

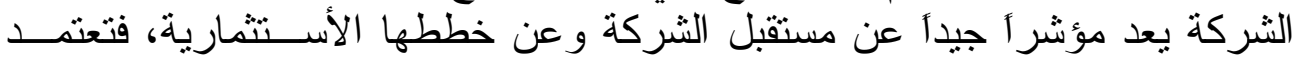

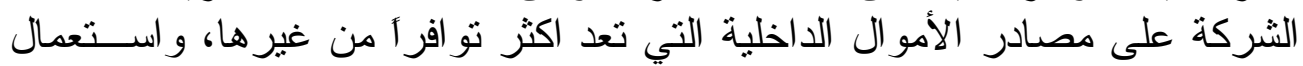

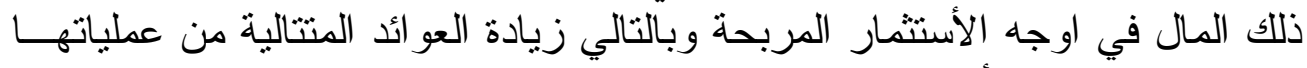

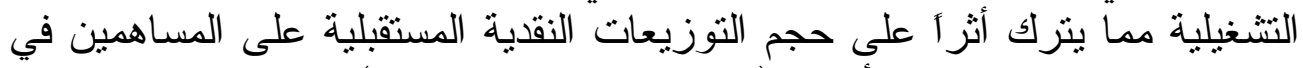
ضوء ثبات سياسة توزيع الأرباح (Kato and Tsay, 2002,8) . فضلا عن ما تقدم فالثركات التي يكون سعر سهمها عال عال تقوم بعملية الرسملة

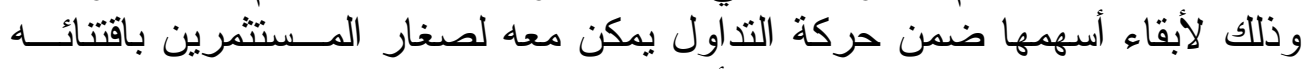

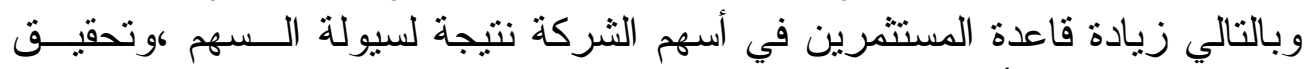

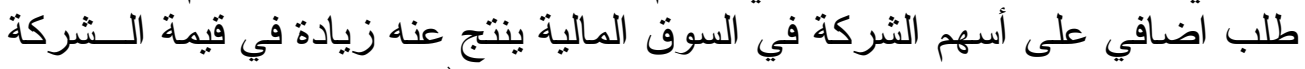

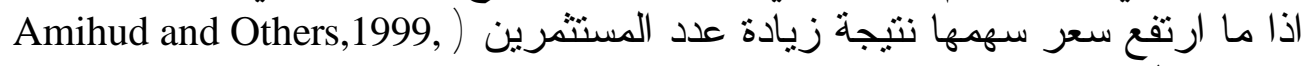
(Abstract

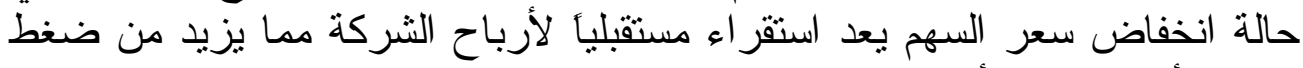

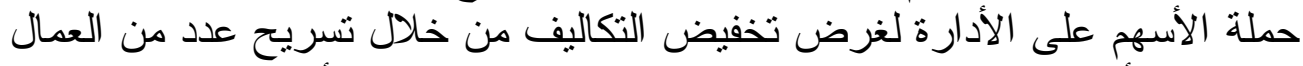

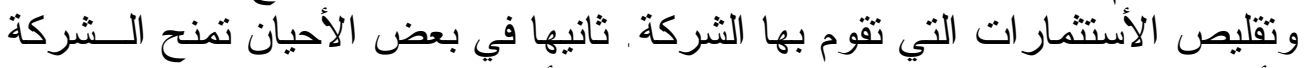

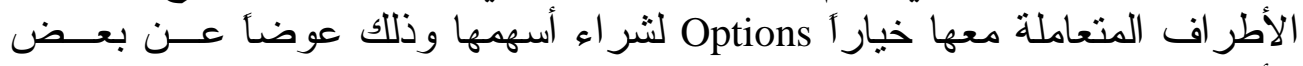

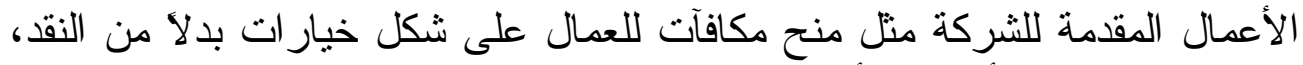

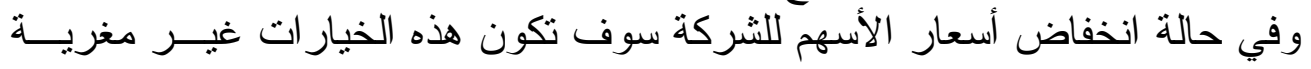


بالنسبة لأطر اف التعامل مع الثركة و احتمال الأمتتاع عن الحصول عليها و المطالبة

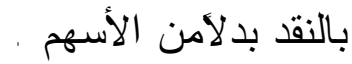
وثالثها العو امل التي تعمل على انخفاض أسعار الأسهم نوعياً تحث المستثرين

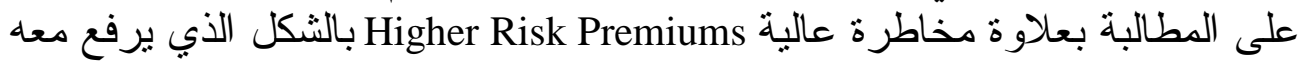

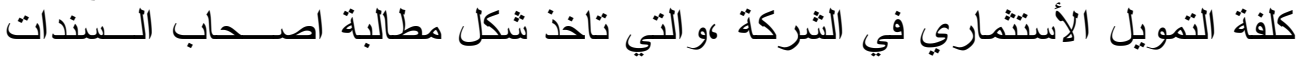

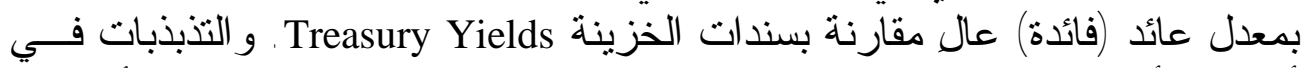

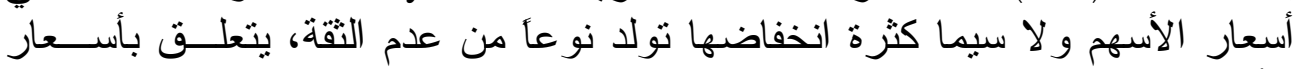

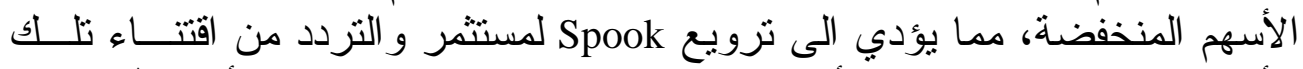

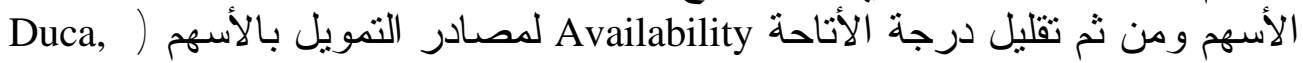
. (2001, 1

\section{سابعاً - مفهوم حركة أسعار الأسهم والنظريات الخاصة به}

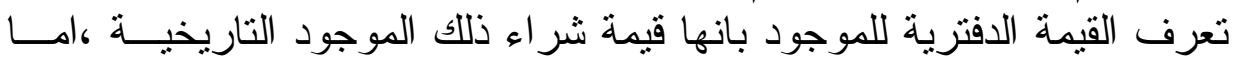

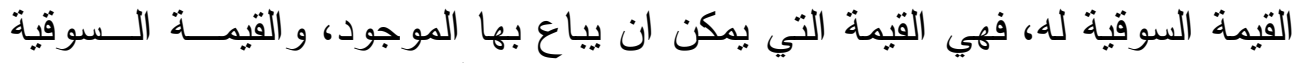

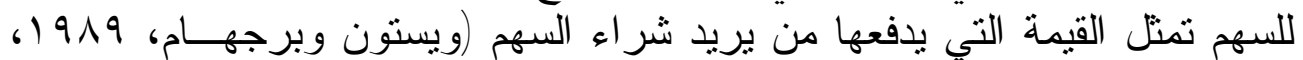

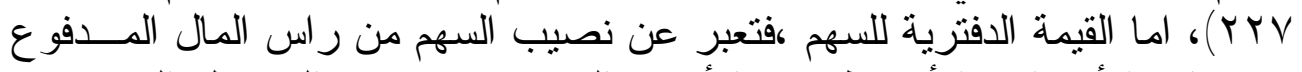

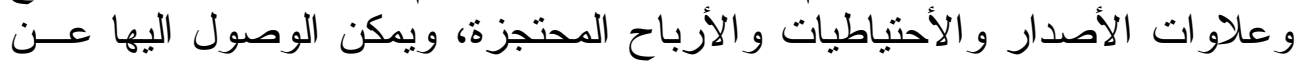

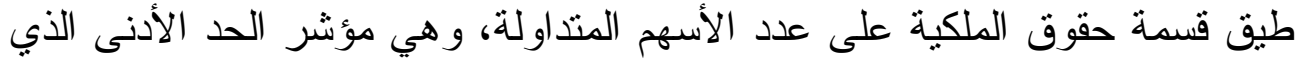

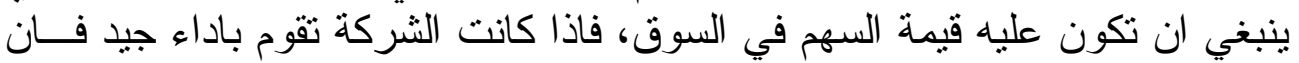

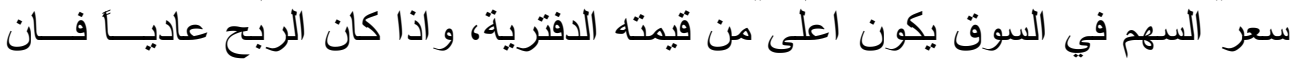

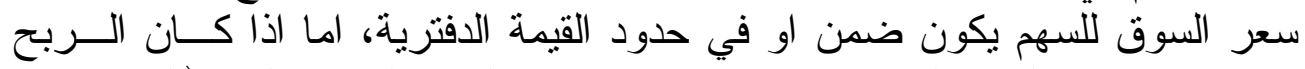

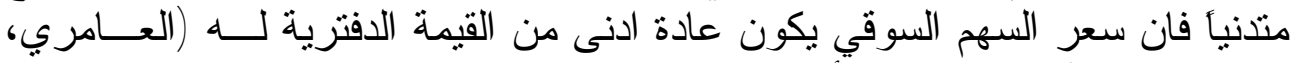

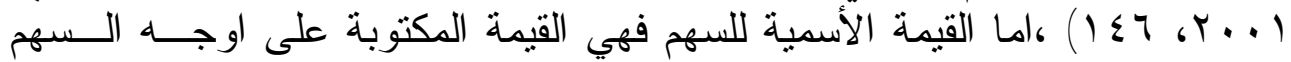

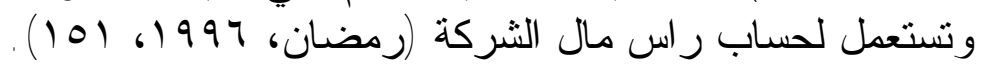

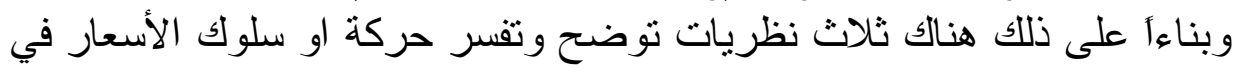

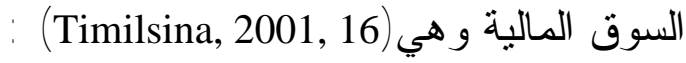

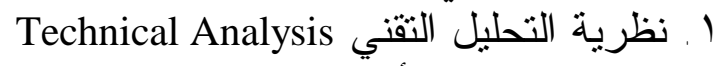

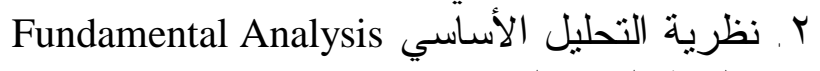

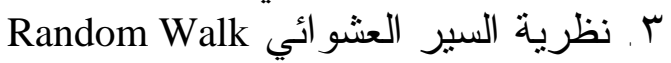

ا ـ نظرية التحليل التقني

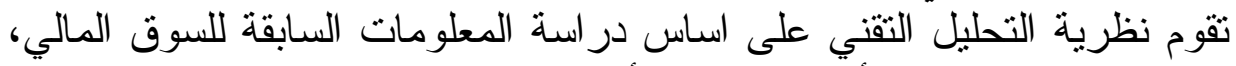

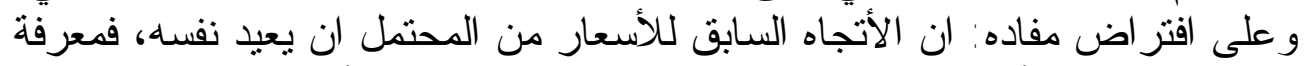

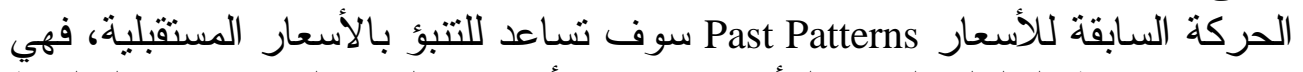

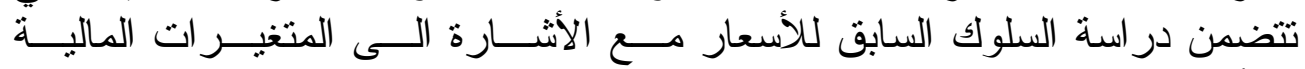

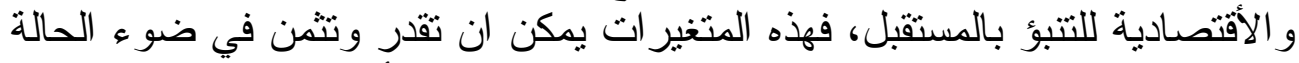

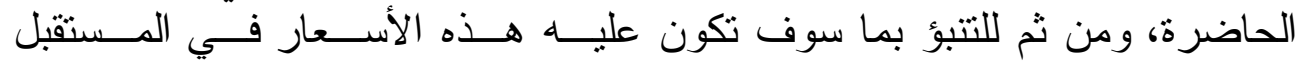




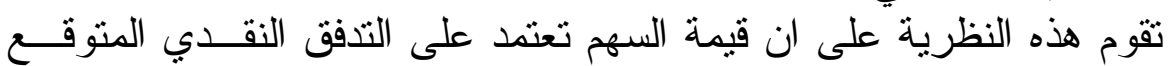

\section{r ب نظرية التحليل الأساسي}

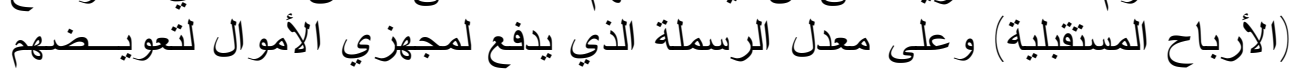

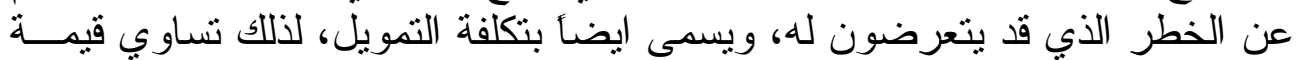

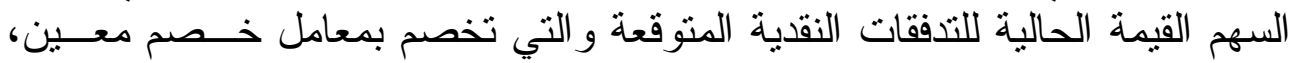

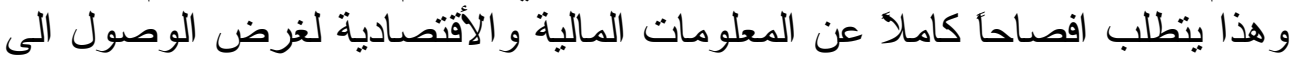

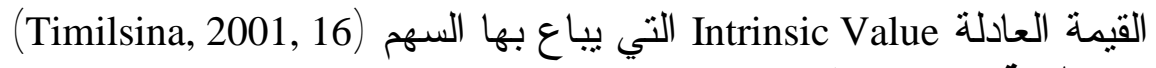

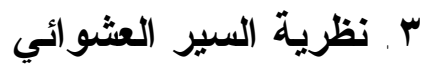
تفترض هذه النظرية بان كل التدفقات النقدية المستقبلية الناتجة عن الأســتثمار

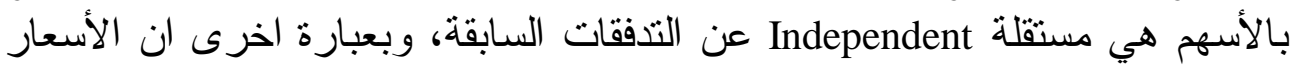

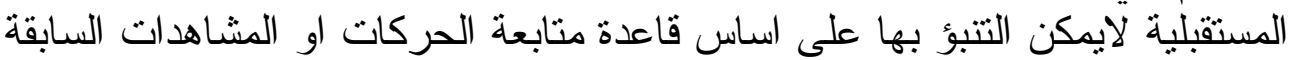

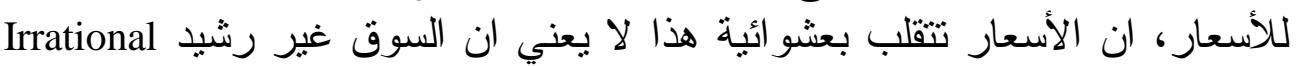

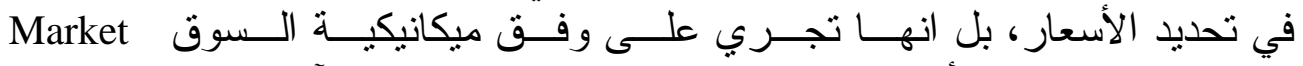
Mechanism

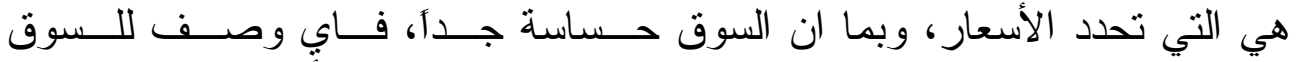

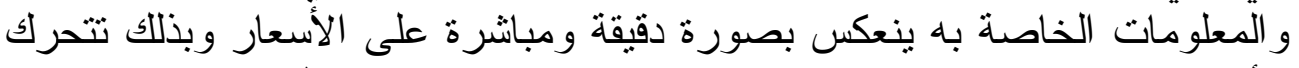

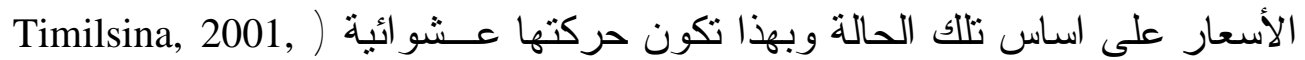

\section{ثامناً - نماذج حركة الأسعار (التحليل التقتي)}

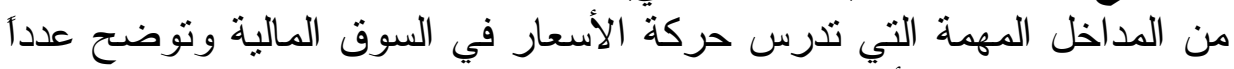

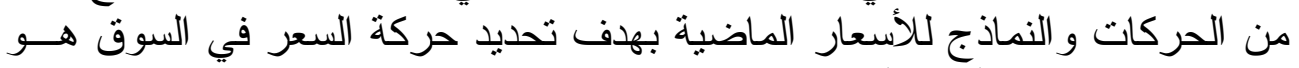

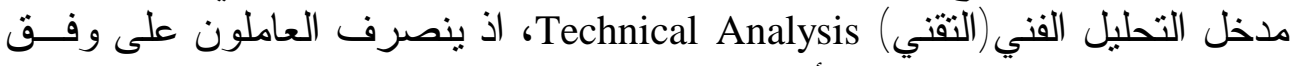

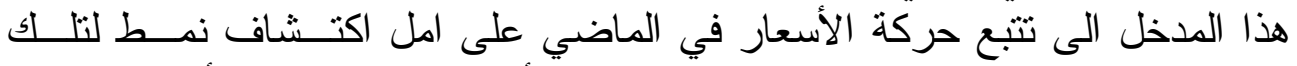

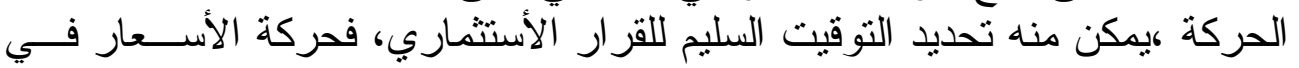

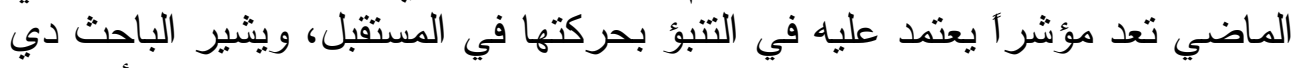

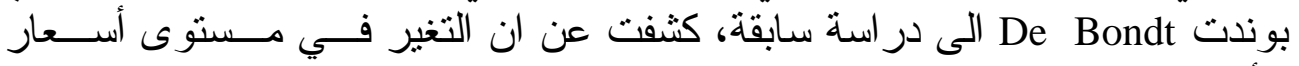

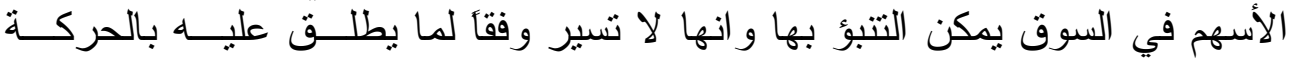

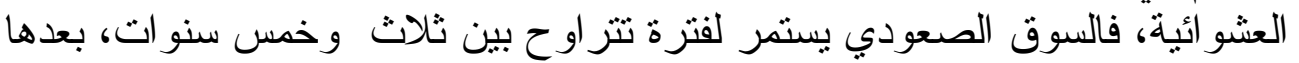

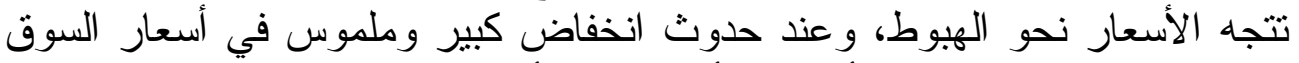

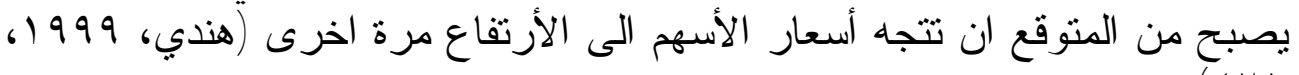

وتعد طريقة دو Dow theory من اقدم و اشهر ادوات التحليل الفنـي لأســــار

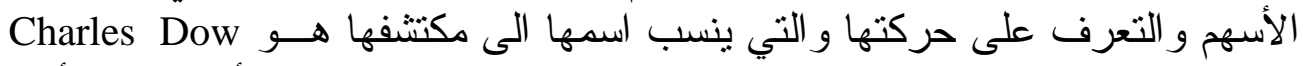

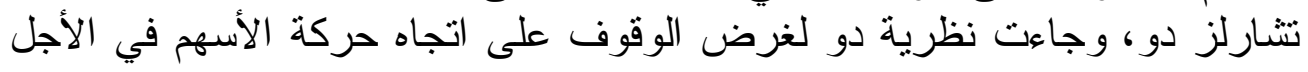

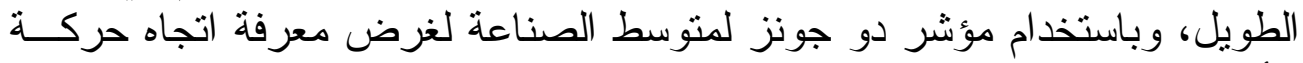

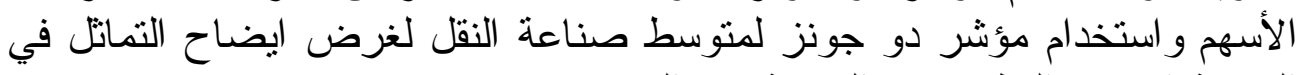
الحركة او عدم التطابق في الحركة بين المؤشرين (Bodi and Others,1998,414). 
تشير النظرية الى وجود ثلاث حركات سعرية لأسعار السوق تحدث في ذاته، الوقت

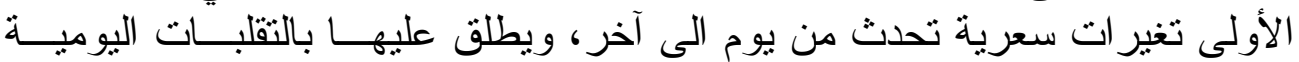

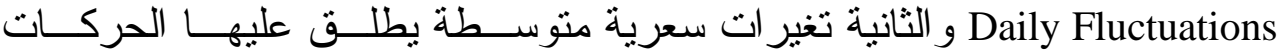

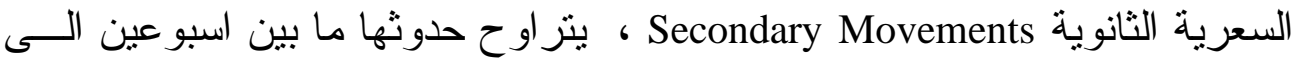

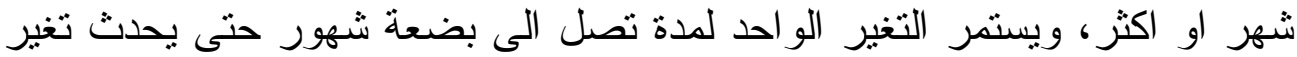

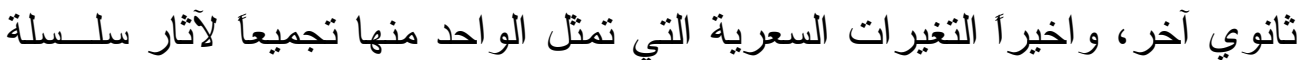

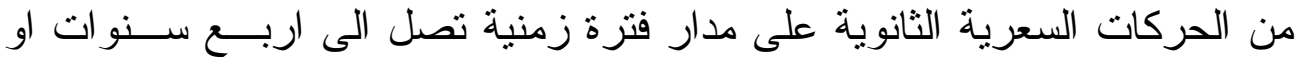

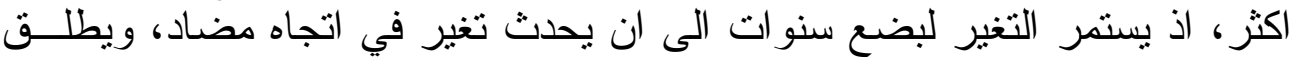

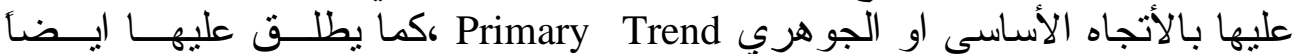

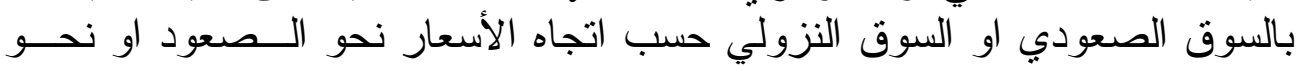

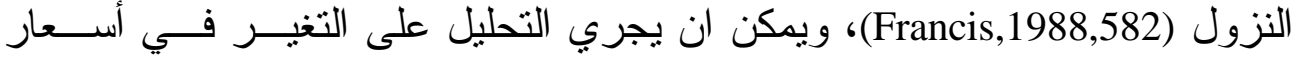

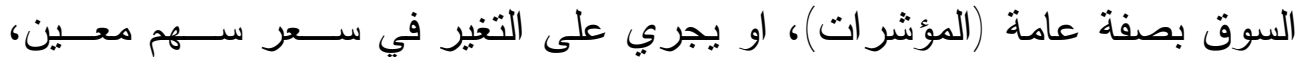
ويوضتح الثكل ب خريطة تلخص نظة الثرية دو :

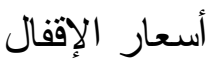

حركة ثانوية

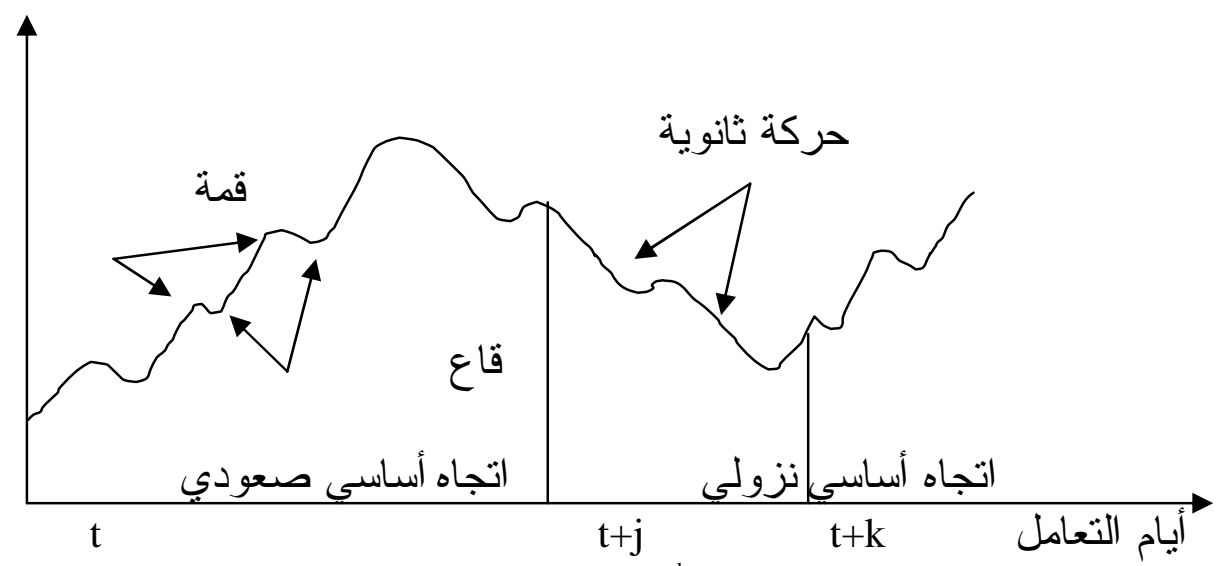

Source:Francis, 1988,Management of Investments, $2^{\text {nd }}$.,McGraw- Hill .N.Y ,583

\section{الشكل \\ مفهوم نظرية دو في حركة الأسعار}

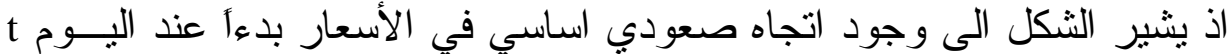

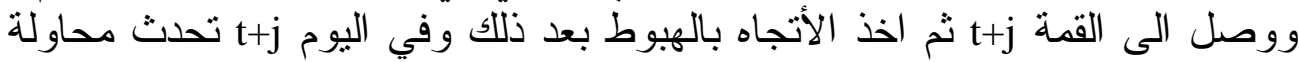
من خلال حركة سعرية ثانوية لأعادة الأسعار الى مستوى القمة الـسابق، ولكنهــا تفشل معلنة بذلك عن تغير في الأتجاه الأساسي، وذلك من الأنسار اتجاه صعودي الى اتجاه 


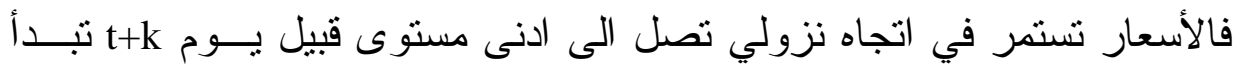

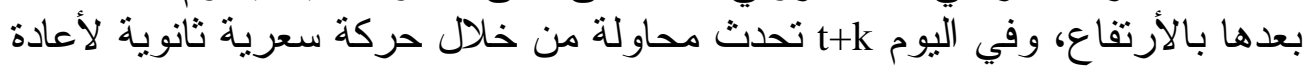

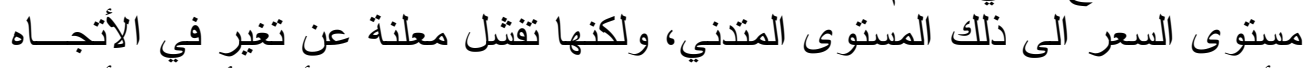

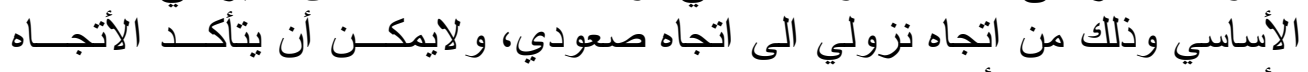

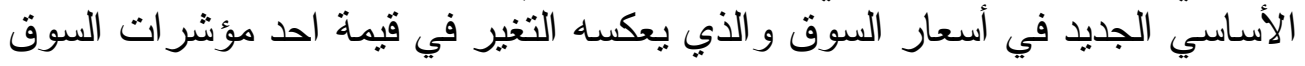

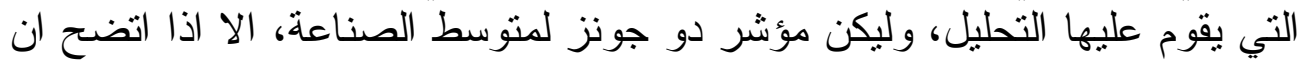

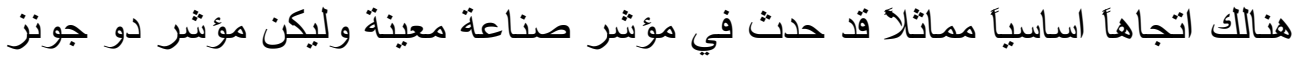
لجنوسط النقل (Francis, 1988,583).

نستخدم الأنحدار المجمع او المتسلسل لغرض تنيان اثر المتغيرات المستقلة على المئ

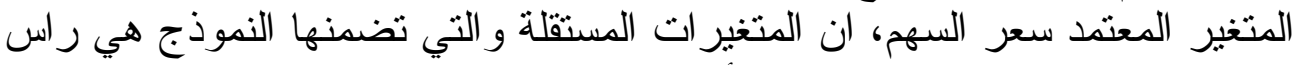

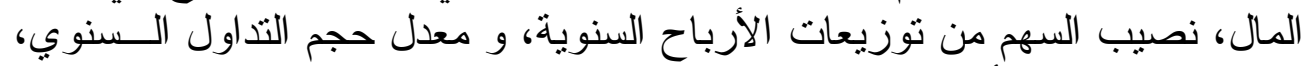

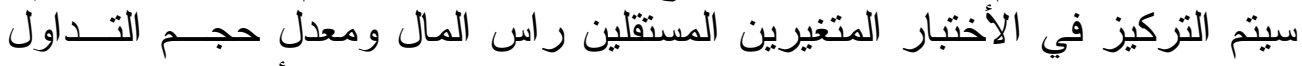

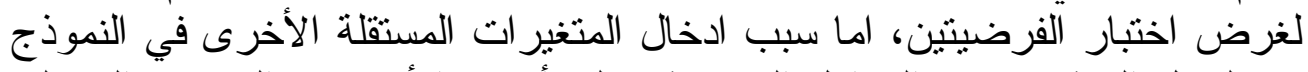

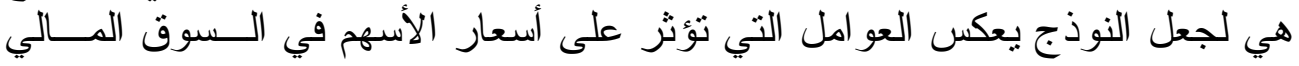

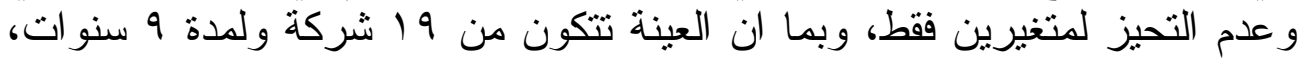

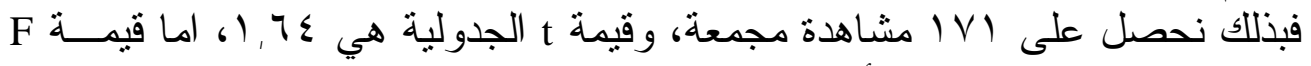

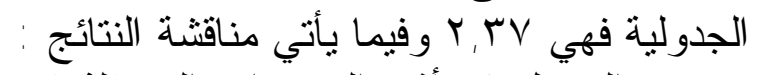

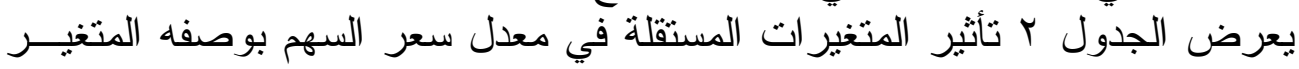

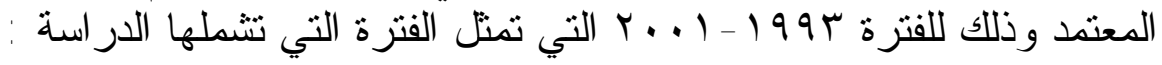

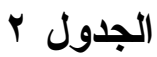

تأثير المتغيرات المستقلة على سعر السهم خلال مدة الاراسة

\begin{tabular}{|c|c|c|c|c|c|c|c|}
\hline $\mathrm{F}$ & $\mathrm{R}^{2}$ & معدل & السهيب من التوزيعات & نصيب السهر من & المال & $\mathrm{B}_{0}$ & المتغير ات المستقلة \\
\hline \multirow{2}{*}{$35.98 *$} & \multirow{2}{*}{$51 \%$} & 0.273 & - 0.018 & 0.326 & - 0.213 & 1.13 & \multirow{2}{*}{ معدل سعر السهر } \\
\hline & & $5.26^{*}$ & -0.27 & $5.17^{*}$ & $-2.9^{*}$ & $2.86^{*}$ & \\
\hline
\end{tabular}

الجدول من مخرجات الحاسوب الألكثروني .

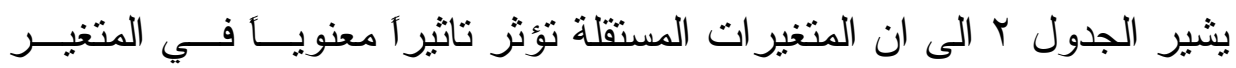

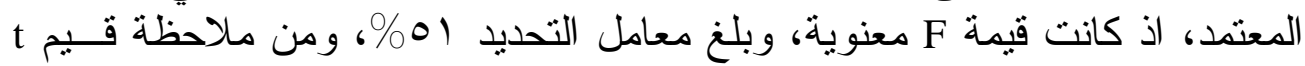

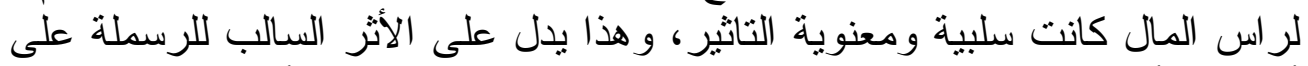

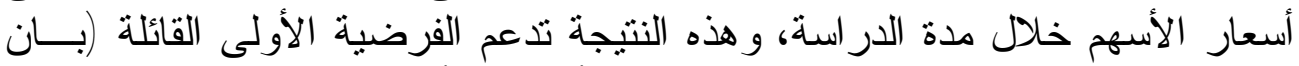

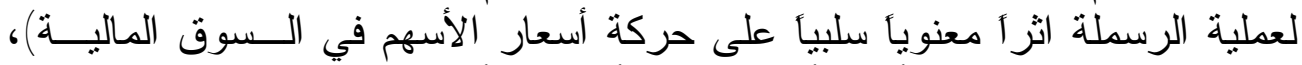

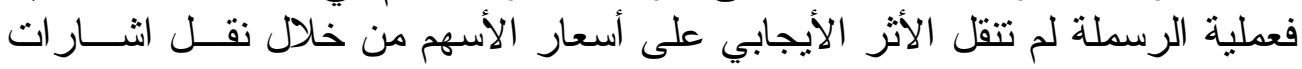

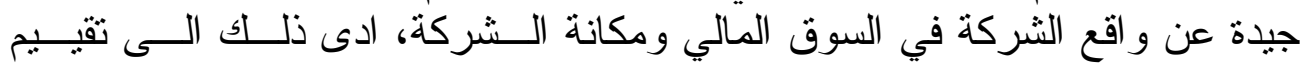


المستثرين لأسهم الثركة بصورة عبرت عن مضمون ادر اكهم لعمليات الرســملة

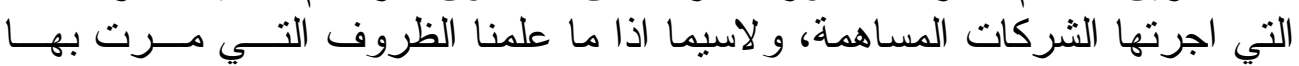

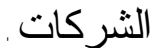

اما بالنسبة لحجم التداول فتظهر قيمة t موجبة الأشارة ومعنوية وبذلك يدل الأثر

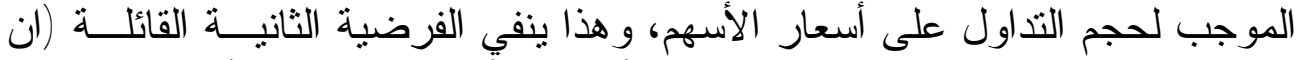

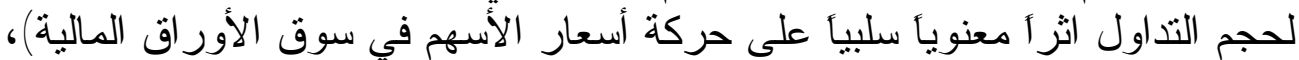

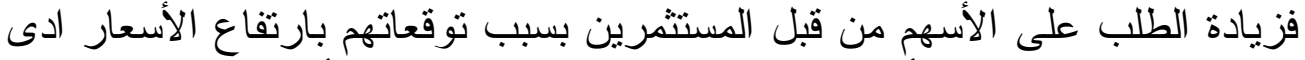

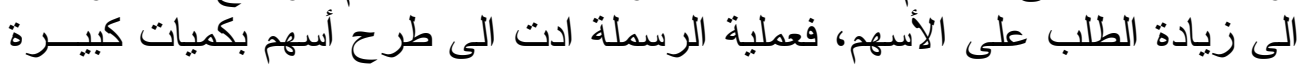

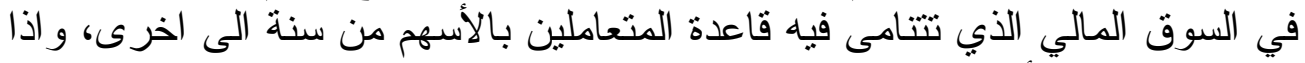

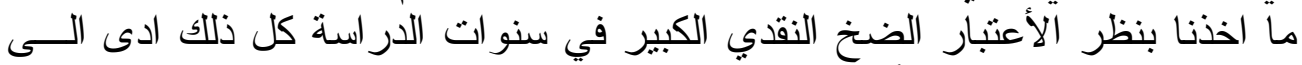

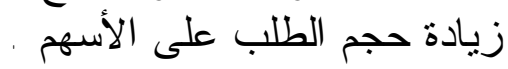

\section{النتائج والتوصيات}

اولاًا - التنائج

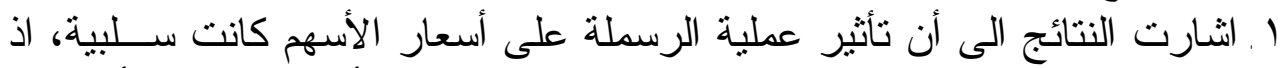

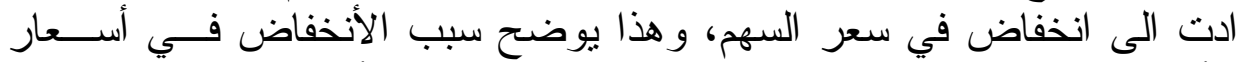

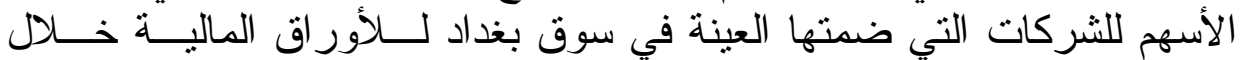

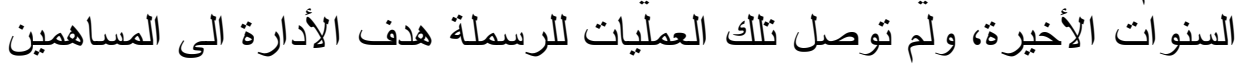

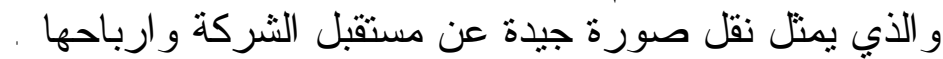

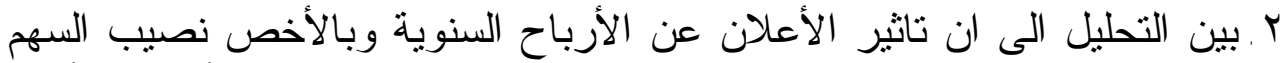

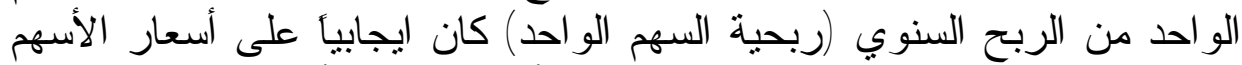

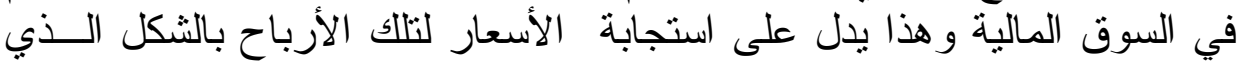
يرفع من قيمة السهم. r. اثثارت النتائج الى أن تأثثر حجم التداول على أسعار الأسهم كان ايجابياً، ومن

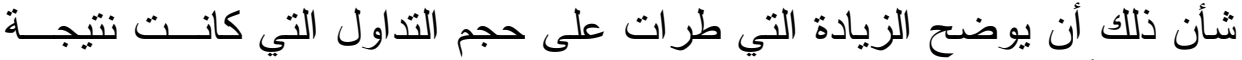
لتداول الأسهم من قبل المستثمرين في السوق المالي بشكل كبير لسببين مهمــين

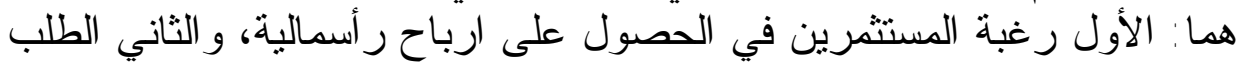
الناتج عن التضخم النقدي.

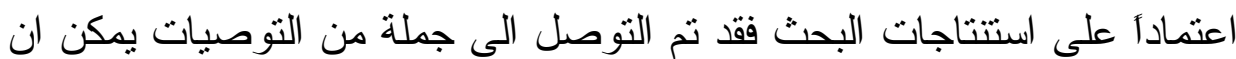

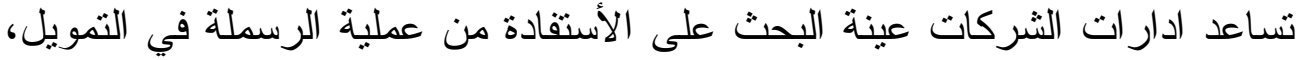

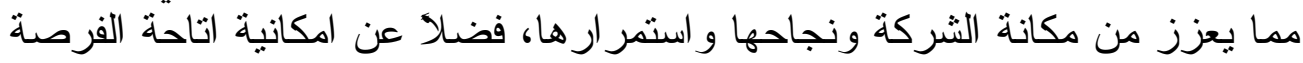

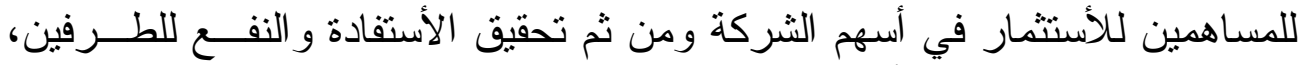

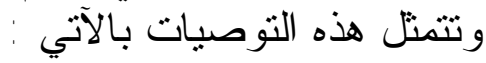

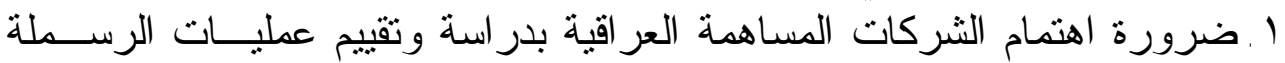

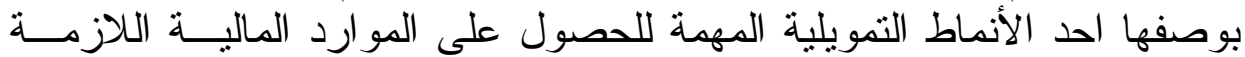


لأحتياجات الثركة، وما توفره من امو ال ملكية بمكن التصرف بها بمرونة وفق واتق

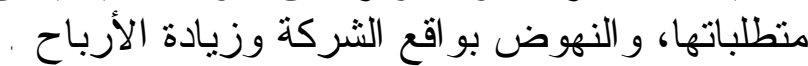

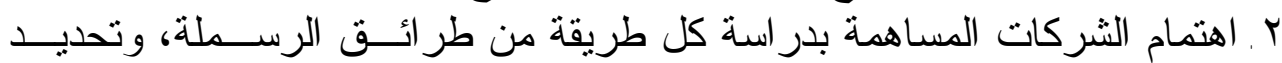

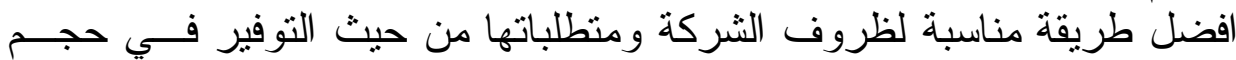

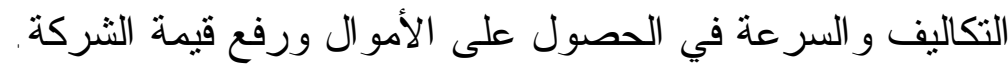

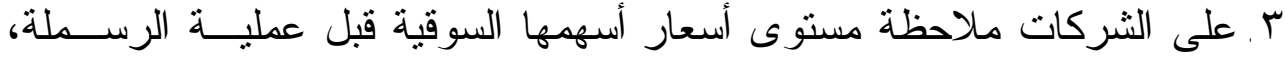

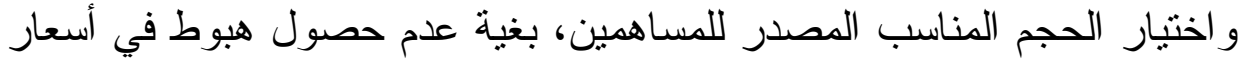

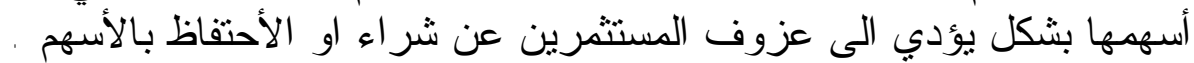

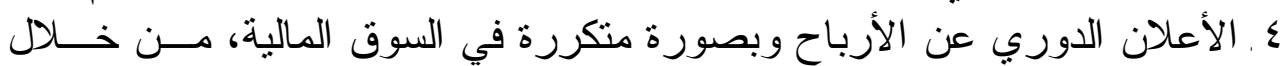

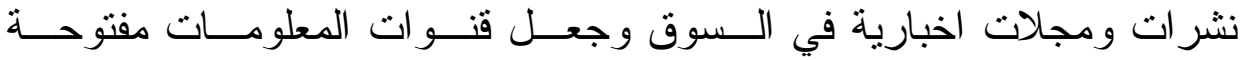

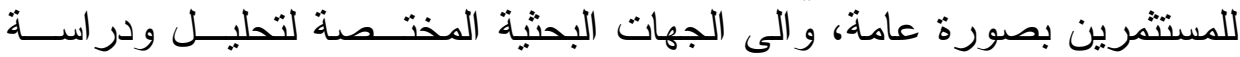
الثركات بصورة عامة، لغرض ابقاء المستثرين على اطلى التلاع على و اقع الثركة

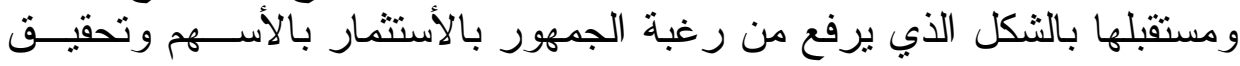

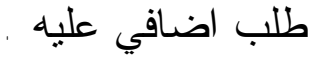

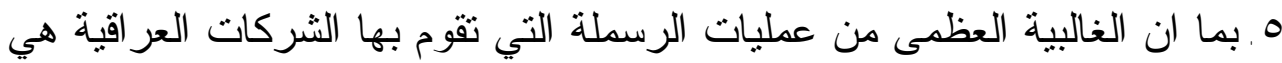

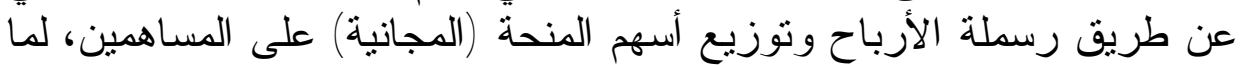

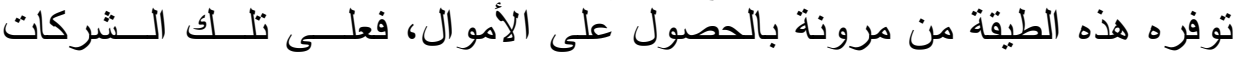
الأعلان عن زيادات في مقسوم الأرباح النقدي، لغرض على تشجيعهم على على الأحتفاظ

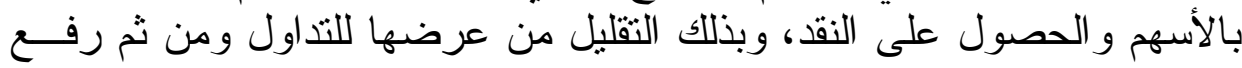
قبمتها

7 . ضرورة قيام سوق بغداد للأور اق المالية باعادة النظر بوسائل نشر المعلومــات

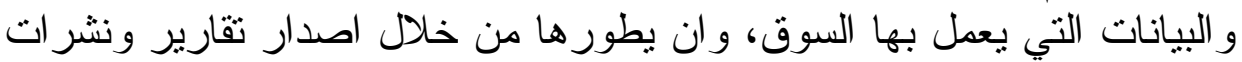

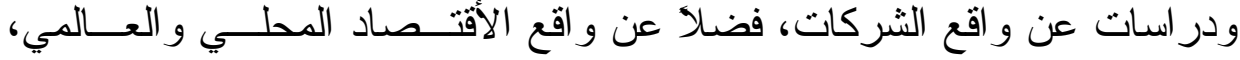

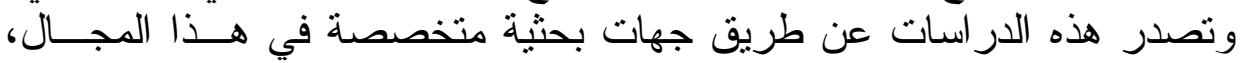

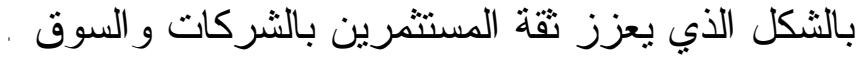

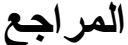 \\ اولاً - المراجع باللغة العربية العزبية}

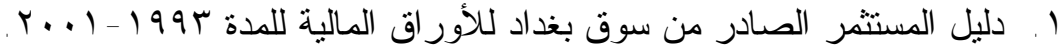

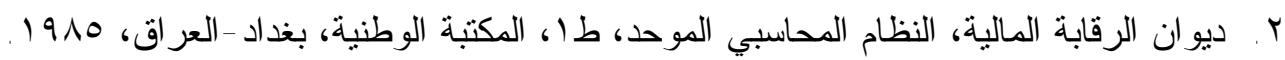

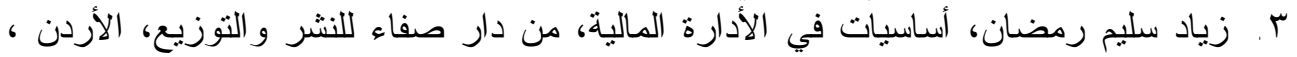
.1997 ع. سرمد كوكب الجميل، أهمية التتبؤ في التحليل المالي، مجلة المساهم، العدد الخامس،

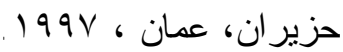

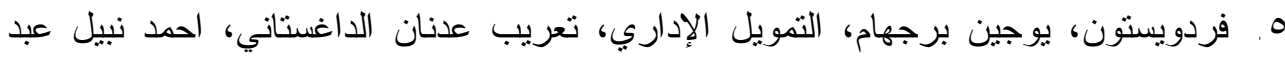

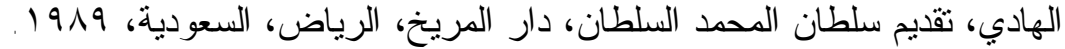

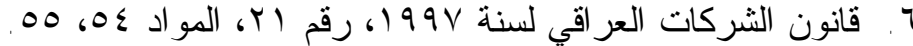




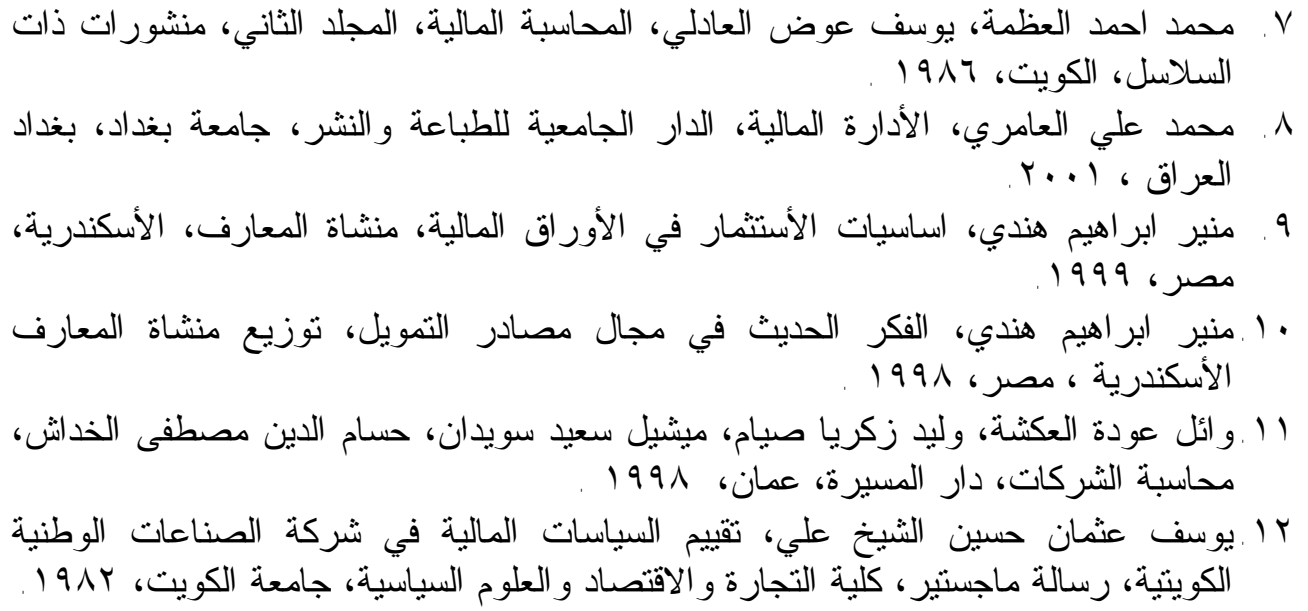

\section{ثانياً - المصادر باللغة الأجنبية}

1. A. S. Hornby,Oxford Students Dictionary Of Current English ,U.K,1978 .

2. Aswath Domodaran, Corporate Finance Theory And Practice, Johnwiley and Sons,Inc , New York , 1997.

3. Charles, O.Kronke Erwin Esser Nemmers, Alan E. Grunewald,1978, Manageral Finance Essentails, $2^{\text {th }}$ ed. , West Puplishing Co. , N.Y.

4. Damodar N.Gujarati, Basic Econometrics, $3^{\text {rd }}$ ed.,McGraw-Hill Co., Singapore, 1995.

5. David A. Dubofsky, Dan W. French, Share Priece Level And Risk : Implications For Financial Management, Journal Of Managerial Finance, Vol. 14 , Iss. 1, 1988.

6. E. F. Castle, N .P. Owens,Priciples Of Accounts, Macdonald ,London, 1981 .

7. E. J. Melaney, Business Finance Theory And Practice, $5^{\text {th }}$ ed., Financial Times, Prentice Hall, U.K, 2000 .

8. Graham Bannok, R. E. Baxter, Ray Rees, The Pengiun Dictionary Of Economics, Pengiun Books Ltd., U. K, 1982 .

9. Hideaki Kiyoshi kato, Wenyuth Tsay, Are Stock Devidends (Mushos) Melons or Lemons in Japan? Journal Of pacific -Basin Finance, Vol. 10 , Iss, 2002.

10. Hyan-Han Shin, Rene M. Stulz, Firm Value, Risk, And Growth,2000.

11. Jack Clark Francis, Management Of Investments, 2nd ed ., Mc Graw-Hill, New York, 1988.

12. James C. Van Horne, Fundamentals Of Financial Management, $4^{\text {th }}$ ed., Prentice-Hall of India, 1982.

13. John V. Duca, The Controvesial Stock Wealth Effect,Apresentation to the Bordof Directors Of The Federal Reserve Bank Of Dallas,Research Department,2001.

14. Mark Conrad, An Easy High-Performance Strategy For Long-term Investors, Journal Of fact: the Money Mgmt Magazine, Vol.6, Iss.2. April,1987 .

15. Merry L .Mosbacher, Daniel A. Burkhardt, Gas Company Stock Splits-have they Increased Trading Activity? Journal Of Puplic Utilities Fortnightly,Vol. 122, Iss. 10,1988 .

16. Opportunities,www.cob-ohiotyateedv/fin/dice/papers/2000-8. Pdf.

17. Philips E. Fess, Carl, S. Wrrem, Accounting Priciples, $14^{\text {th }}$ ed., South-Westeren Puplishing Co., USA, 1984 .

18. Robert F. Megs, Walter B. Meigs, Accounting The Basis For Business Decision, $6^{\text {th }}$ ed., McGraw-Hill , New York, 1984.

19. Stanley B. Block, Geofrey A. Hirt, Foundation Of Ginancial, Management, $7^{\text {th }}$ ed., Irwin, USA, 1992. 
كوكب و العبادي [ov] الرسملة وعلاقتها بحركة اسعار الاسهم ... - مجا.

20. Stephen A. Ross, Randolph W. Wester Field, Bradford D. Jordan, Essentails Of Corporate Finance, Irwin , USA, 1996.

21. Yakov Amihod, Haim Mendelson, Jun Uno, Number Of Shareholders And Syock Price : Evidence From Japan, Journal Of Finance, Vol. 54 , Issue 3,1999.

22. Yogendra Timilsima, Capital Market Development And Stock Prices Bahaviour In Nepal, Economic Review : Occational Paper, Number

23. www.nrb.org.np/pubs/economic-review-occational-paper-no-13captal market.pdf,2001.

24. Zvi Bodi, Alex kane, Alan J. Marcus, 1998, Essentials Of Investment, $3^{\text {rd }}$ ed., Irwin , McGraw-Hill, USA.

25. http:/web.wellinvested.com/topics/understanding/why.htm.2003 .

26. http:gsb.uchicago.edu/pdf/sp16.pdf .

\title{
The Capitalization and Its Relation With Stocks Prices Movement Applied in a Sample of Cooperative Firms Registered in Baghdad Stock Exchanges For The Period (1993-2001)
}

\begin{abstract}
The study deals with the analysis effect between Capitalization process of the Cooperative Firms and Stock Price Movement. In the Framework of a sample of Iraqi Cooperative Firms with in the Industrial Sector that registered at Baghdad Stock Exchange (B.S.E), The study is directed towards finding solutions for many questions to the nature of Capitalization and the prices of Stock market and the influence of Capitalization on Stock Prices. Aimed in such context the study gives a background on the concept, The importance and The mapping of Capitalization among Cooperative Firms as well as identifying the movement of stock prices.
\end{abstract}

